\title{
Autocrine motility factor/phosphoglucose isomerase regulates ER stress and cell death through control of ER calcium release
}

\author{
$\mathrm{M} \mathrm{Fu}^{1}, \mathrm{~L} \mathrm{Li}{ }^{1}, \mathrm{~T}$ Albrecht ${ }^{1}$, JD Johnson ${ }^{1}$, LD Kojic ${ }^{1}$ and IR Nabi, ${ }^{\star 1}$
}

Autocrine motility factor/ phosphoglucose isomerase (AMF/PGI) promotes cell survival by the pAkt survival pathway. Its receptor, gp78/AMFR, is an E3 ubiquitin ligase implicated in endoplasmic reticulum (ER)-associated protein degradation. We demonstrate here that AMF/PGI also protects against thapsigargin (TG)- and tunicamycin (TUN)-induced ER stress and apoptosis. AMF/PGI protection against the ER stress response is receptor mediated as it is not observed in gp78/AMFRknockdown HEK293 cells. However, AMF/PGI protection against the ER stress response by TG and TUN was mediated only partially through PI3K/Akt activation. AMF/PGI reduction of the elevation of cytosolic calcium in response to either TG or inositol 1,4,5-trisphosphate receptor activation with ATP was gp78/AMFR-dependent, independent of mitochondrial depolarization and not associated with changes in ER calcium content. These results implicate regulation of ER calcium release in AMF/PGI protection against ER stress and apoptosis. Indeed, sequestration of cytosolic calcium with BAPTA-AM limited the ER stress response. Importantly, elevation of cytosolic calcium upon treatment with the calcium ionophore ionomycin, while not inducing an ER stress response, did prevent AMF/PGI protection against ER stress. By regulating ER calcium release, AMF/PGI interaction with gp78/AMFR therefore protects against ER stress identifying novel roles for these cancer-associated proteins in promoting tumor cell survival.

Cell Death and Differentiation (2011) 18, 1057-1070; doi:10.1038/cdd.2010.181; published online 21 January 2011

The endoplasmic reticulum (ER) comprises a complex membranous network that has a crucial role in normal cellular function, particularly with regard to folding and post-translational modification of secretory and membrane proteins. ${ }^{1}$ To accomplish its protein folding function, the ER contains high concentrations of chaperone proteins, which facilitate correct folding of nascent proteins. Many of these chaperones are calcium $\left(\mathrm{Ca}^{2+}\right)$ dependent, and in fact, the ER contains high concentrations of $\mathrm{Ca}^{2+}$ and has an important role in intracellular $\mathrm{Ca}^{2+}$ homeostasis. ${ }^{2}$ Disruption of ER function can occur as a result of a wide variety of cellular stress stimuli, many of them related to cancer development, reducing protein folding capacity, and leading to the buildup of unfolded and misfolded proteins within the ER. ${ }^{3}$ The cell responds by inhibiting protein synthesis, enhancing protein folding capacity through expression of ER chaperone proteins, including $\mathrm{BiP}$ (also known as glucose regulated protein 78, GRP78), and degrading misfolded proteins through a process called ER-associated degradation (ERAD). This coordinated biochemical response to the accumulation of unfolded and/or misfolded proteins within the ER is termed the unfolded protein response (UPR). ${ }^{4}$
Induction of the UPR occurs when the presence of unfolded proteins in the ER exceeds the capacity of the ER to correctly fold these proteins. UPR is associated with a number of normal biological processes, such as induction of antibody production in B cells, as well as with disease states in which it disrupts cell function and induces cell death. ${ }^{5}$ Induced in response to hypoxia, nutrient deprivation and low $\mathrm{pH}$ of the tumor microenvironment, ER stress contributes to tumor cell survival and can be required for tumor growth; indeed, expression of various ER chaperones, including $\mathrm{BiP}$, is upregulated in various cancers. ${ }^{6}$ Both inhibition of UPR, resulting in a limited ability of the cell to deal with the stressful environment, or enhancing stress and overloading the UPR represents a possible approach to drive cancer cells towards apoptosis. ${ }^{7}$ However, effectiveness of any such anti-cancer strategy will be dependent on understanding the mechanisms underlying cancer cell resistance to ER stress induction.

In the event of prolonged or severe ER stress that is not resolved, the UPR switches to initiation of apoptosis. ${ }^{8}$ Certain components of the UPR are strongly linked to induction of ER stress-induced apoptosis. In this regard, CHOP is induced by all three arms of the UPR through XBP1, ATF4 and ATF6

\footnotetext{
${ }^{1}$ Department of Cellular and Physiological Sciences, Life Sciences Institute, University of British Columbia, Vancouver, British Columbia, Canada

${ }^{*}$ Corresponding author: IR Nabi, Department of Cellular and Physiological Sciences, Life Sciences Institute, University of British Columbia, 2350 Health Sciences Mall, Vancouver, British Columbia V6T 1Z3, Canada. Tel: + 1604822 7000; Fax: + 1604822 2316; E-mail: irnabi@interchange.ubc.ca

Keywords: autocrine motility factor/phosphoglucose isomerase (AMF/PGI); gp78/AMFR; endoplasmic reticulum stress; apoptosis; cellular calcium Abbreviations: AMF/PGI, autocrine motility factor/phosphoglucose isomerase; $\mathrm{AUC}$, area under the curve; $\mathrm{Ca}^{2+}$, calcium; $\left[\mathrm{Ca}^{2+}\right]_{\text {cyt }}$, cytosolic calcium concentration; $\left[\mathrm{Ca}^{2+}\right]_{\mathrm{m}}$, mitochondrial calcium concentration; $\left[\mathrm{Ca}^{2+}\right]_{\text {ext }}$, extracellular calcium concentration; $\left[\mathrm{Ca}^{2+}\right]_{\mathrm{ER}}$, endoplasmic reticulum calcium concentration; $\mathrm{CCCP}$, carbonyl cyanide $m$-chlorophenylhydrazone; ER, endoplasmic reticulum; ERAD, ER-associated protein degradation; FRET, fluorescence resonance energy transfer; Gp78/AMFR, glycoprotein 78/autocrine motility factor receptor; $I_{3} R$, 1, 4, 5-trisphosphate receptors; SERCA, sarco/endoplasmic reticulum Ca ${ }^{2+}$-ATPase; TG, thapsigargin; TUN, tunicamycin; UPR, unfolded protein response

Received 15.4.10; revised 15.11.10; accepted 30.11.10; Edited by M Piacentini; published online 21.1.11
} 
transcription factors, and is required in many instances for ER stress-induced apoptosis. ${ }^{9}$ ER stress is also associated with the release of $\mathrm{ER} \mathrm{Ca}^{2+}$, whose uptake by mitochondria is a critical regulator of cellular $\mathrm{Ca}^{2+}$ homeostasis and of the mitochondrial apoptosis pathway. ${ }^{10,11}$ Indeed, prolonged ER stress conditions cause a slow but sustained increase in mitochondrial matrix free $\mathrm{Ca}^{2+}$, that upon reaching a critical threshold is one of the strongest inducers of pro-apoptotic mitochondrial membrane permeabilization. $^{12}$ Truncated sarcoplasmic reticulum $\mathrm{Ca}^{2+}$ ATPase 1 has been shown to promote pro-apoptotic ER-mitochondria $\mathrm{Ca}^{2+}$ transfer during ER stress. ${ }^{13}$ However, other mechanisms regulating this process remain poorly understood.

AMF/PGI is a glycolytic enzyme that also functions as an extracellular cytokine following secretion by a non-classical mechanism. Autocrine activation of its receptor gp78/AMFR has been extensively associated with tumor cell motility and metastasis. ${ }^{14}$ AMF/PGI overexpression in NIH-3T3 cells has been shown to induce cellular transformation and tumorigenicity, as well as tumor cell survival by PI3K/Akt signaling. ${ }^{15}$ In addition to its role as the AMF/PGI receptor, gp78/AMFR is also an ER membrane-anchored ubiquitin ligase (E3) that is a key component of the ERAD pathway. ${ }^{14}$ To specifically assess whether AMF/PGI regulates ER-associated survival, we tested its ability to protect against the ER stress response. We show that exogenous AMF/PGI protects against ER stress and associated cell death, and that this activity is dependent on expression of its receptor, gp78/AMFR. We further demonstrate that PI3K/Akt signaling only partially regulates $A M F / P G I$ protection against $E R$ stress and describe a novel role for gp78/AMFR-mediated AMF/PGI regulation of $\mathrm{ER} \mathrm{Ca}^{2+}$ release that functions to limit ER stress and promote cell survival.

\section{Results}

AMF/PGI treatment prevents the tunicamycin and thapsigargin-induced ER stress response and associated apoptotic events. Incubation of Cos7 cells with tunicamycin (TUN), an inhibitor of N-glycosylation, or thapsigargin (TG), a sarco/endoplasmic reticulum $\mathrm{Ca}^{2+}$-ATPase (SERCA) inhibitor that prevents $\mathrm{ER} \mathrm{Ca}^{2+}$ uptake resulted in the disruption of the tubular calnexin-labeled ER network and its condensation into large vacuoles and densely labeled aggregates. However, in cells pretreated with $24 \mu \mathrm{g} / \mathrm{ml}$ AMF/PGI for $8 \mathrm{~h}$, TUN or TG no longer disrupted the tubular ER network or induced ER vacuoles (Figure 1a). TUN and TG increased expression levels of the major ER chaperone proteins $\mathrm{BiP}$ and $\mathrm{CHOP}$, both associated with the ER stress response. Pretreatment of the cells with AMF/PGI for $8 \mathrm{~h}$ prevented increased $\mathrm{BiP}$ and $\mathrm{CHOP}$ expression induced by either TUN or TG (Figure 1b). AMF/PGI therefore protects against TUN and TG-induced ER stress. ER stress-induced cell death was further characterized by $\mathrm{Pl} /$ Annexin $\mathrm{V}$ double staining by both flow cytometry and immunofluorescence (Figure 1c and Supplementary Figure 1). AMF/PGI pretreatment significantly reduced the number of dead Annexin V/PI-positive cells, demonstrating the ability of $A M F / P G I$ to promote cell survival upon induction of ER stress.
To assess the cytosolic expression of the apoptosisassociated proteins, cleaved caspase-3 and mitochondrial cytochrome $c$, cells were sub-fractionated into cytosol, nuclei, ER/plasma membrane and mitochondrial fractions using $\alpha$-tubulin, $\alpha$-fibrilarin, calnexin and cytochrome $c$ as markers, respectively. The cytosolic and mitochondrial markers, $\alpha$-tubulin and cytochrome $c$, respectively, were highly enriched in these fractions and subsequent analyses were limited to these subcellular fractions. Prolonged TUN and TG treatment to $24 \mathrm{~h}$ induced mitochondrial cytochrome $c$ release to cytosol and upregulation of cleaved caspase- 3 in the cytosolic fraction, consistent with the occurrence of apoptotic death in cells subjected to chronic ER stress. In contrast, AMF/PGI pretreatment prevented TUN and TG-induced cytosolic cytochrome $c$ release and caspase-3 cleavage, suggesting that AMF/PGI-mediated protection from ER stress is caspase- 3 dependent and occurs through the mitochondrial pathway (Figure 2a). Confocal images showed that the extensive overlap of cytochrome $c$ with the mitochondrial marker Oxphos $\mathrm{V}$ in untreated cells was lost upon treatment with either TUN or TG that resulted in cytochrome $c$ release to cytosol. This was prevented in AMF/PGI pretreated cells that still presented extensive overlap between cytochrome $c$ and Oxphos $\mathrm{V}$ labeling even in TUN- or TG-treated cells (Figure 2b).

The DNA-damaging topoisomerase II inhibitor etoposide ${ }^{16}$ does not increase expression of $\mathrm{BiP}$ and $\mathrm{CHOP}$, but does induce expression of cleaved caspase-3. This is consistent with previous reports that etoposide induced cell apoptosis does not occur through the ER stress pathway. ${ }^{17}$ AMF/PGI protected against cell death induced by etoposide, TG and TUN and also inhibited etoposide-induced upregulation of cleaved caspase-3 (Figures $3 a$ and $b$ ). This suggests that AMF/PGI protects against cell death induced not only through the ER stress pathway but also through other mechanisms, consistent with previous reports that AMF/PGI overexpression protects against serum starvation-induced cell death through the PI3K/Akt pathway. ${ }^{15}$

Gp78/AMFR mediates AMF/PGI protection against the ER stress response and apoptosis. The cell surface receptor for AMF/PGI, gp78/AMFR is localized both at the cell surface and in the ER, in which it functions as an E3 ubiquitin ligase in ERAD. ${ }^{14}$ To determine the role of $\mathrm{gp} 78 /$ AMFR in AMF/PGI protection against the ER stress response, we generated stable gp78/AMFR-specific microRNA transfected HEK293 cells (miR2 and miR3) that show a 60-70\% reduction in gp78/AMFR expression compared with non-targeted miRNA control transfected HEK293 cells (NTC1 and NTC2) by western blot analysis (Figure 4a). Using flow cytometry, we found that cell surface gp78/AMFR expression showed $60-80 \%$ reduction in microRNA-transfected HEK293 cells (miR2 and miR3) compared with non-targeted miRNA control transfected HEK293 cells (NTC1 and NTC2) (Figure 4b). As observed previously in Cos7 cells, AMF/PGI decreased TUN and TG-induced $\mathrm{CHOP}$ and cleaved caspase-3 expression in non-targeted control HEK293 cells (NTC1 and NTC2). However, in gp78/AMFR-specific microRNA transfected HEK293 cells (miR2 and miR3), AMF/PGI had no effect on 
a

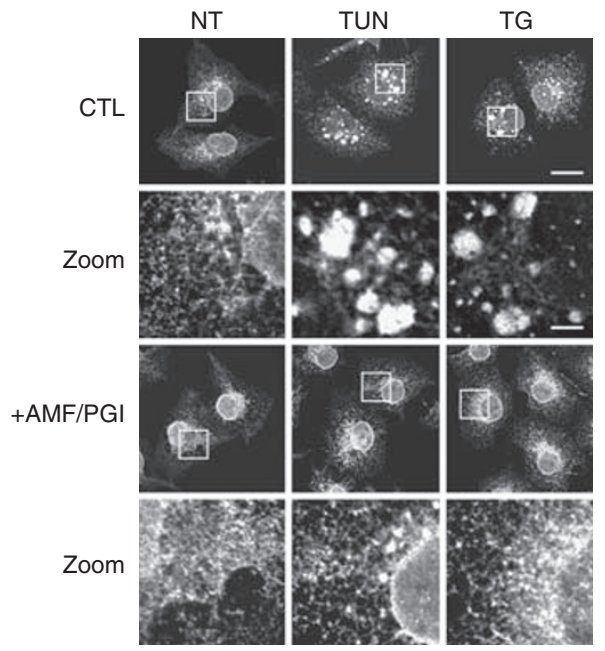

b

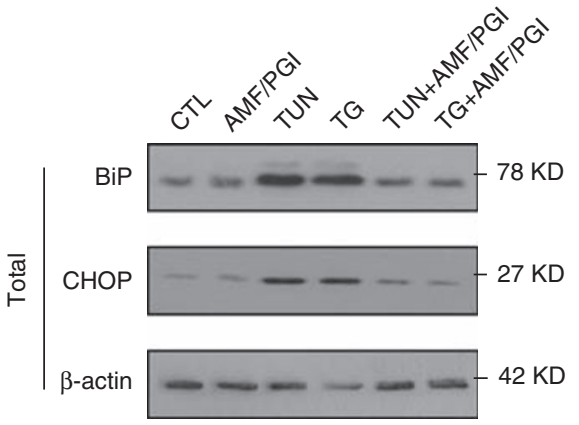

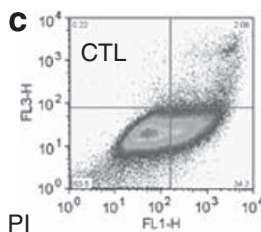

$\mathrm{P}$
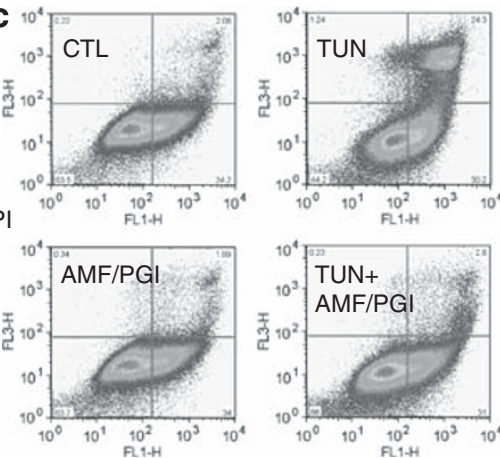

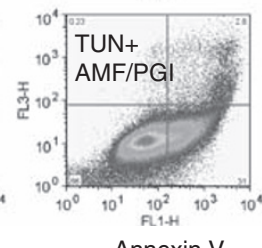

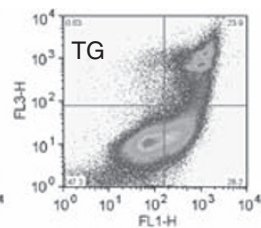

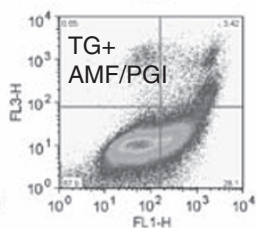

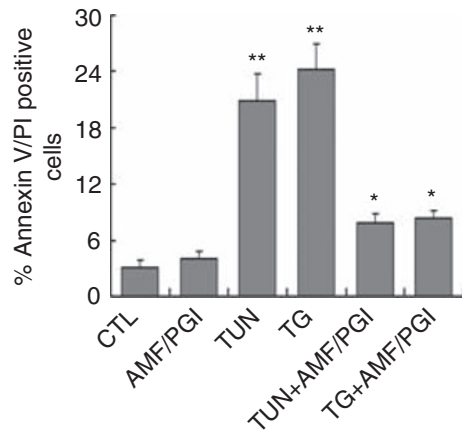

Figure 1 AMF/PGI prevents TUN and TG-induced ER stress response and cell death. (a) Cos7 cells, either untreated (CTL) or pretreated, with $24 \mu \mathrm{g} / \mathrm{ml}$ AMF/PGI ( + AMF/PGI) for $8 \mathrm{~h}$ before addition of $2 \mu \mathrm{g} / \mathrm{ml}$ tunicamycin (TUN) or $3 \mu \mathrm{M}$ thapsigargin (TG) for $8 \mathrm{~h}$ were fixed and immunofluorescently labeled with antibodies to the ER protein calnexin. Scale bar, $30 \mu \mathrm{m}$; in box: $6 \mu \mathrm{m}$. (b) Cos7 cells treated as in a were immunoblotted with antibodies to BiP, CHOP and $\beta$-actin. (c) Cos7 cells treated as in a were double labeled by Annexin V and PI and detected by flow cytometry. Bar graph shows percentage of Annexin V and PI-positive cells (Mean \pm S.E.M.; ${ }^{*} P<0.05$, ${ }^{\star \star} P<0.01$ relative to CTL cells)

ER stress-induced CHOP and cleaved caspase-3 expression (Figure 4c). This indicates that AMF/PGI protection against ER stress and associated apoptosis is mediated by gp78/AMFR.

AMF/PGI prevents the ER stress response in part through the PI3K/Akt cell survival pathway. AMF/PGI has previously been shown to promote cell survival through the PI3K/Akt pathway. ${ }^{15}$ To determine the role of PI3K/Akt signaling in AMF/PGI prevention of the ER stress response, we evaluated the effect of AMF/PGI on CHOP, BiP and cleaved caspase-3 expression upon pretreatment with the PI3K inhibitor, LY294002. As previously reported in NIH-3T3 and MDA-435 cells, ${ }^{15,18}$ AMF/PGI treatment induced activation of pAkt in Cos7 cells that was prevented by the PI3K inhibitor LY294002 (Figure 5). However, LY294002 treatment only partially reversed the inhibition by AMF/PGI of induction of the ER stress markers BiP and $\mathrm{CHOP}$ and of cleaved caspase-3 upon TUN and TG treatment. Expression of all three markers was significantly elevated relative to treatment of ER-stressed cells with AMF/PGI alone, indicating that $\mathrm{PI} 3 \mathrm{~K}$ inhibition is partially reversing the ability of AMF/PGI to protect against the ER stress response. However, marker expression levels were reduced relative to levels induced by TUN and TG in the absence of AMF/PGI. This suggests that AMF/PGI protects against the ER stress response and associated cell apoptosis only partially through the PI3K/Akt cell survival pathway and that other mechanisms must also be involved.

AMF/PGI suppresses cytosolic $\mathrm{Ca}^{2+}$ homeostasis. $\mathrm{Ca}^{2+}$ is a key regulator of cell survival and sustained elevation of cytosolic $\mathrm{Ca}^{2+}$ released from the $\mathrm{ER}$, resulting in mitochondrial $\mathrm{Ca}^{2+}$ overload can directly induce apoptotic signals by releasing apoptosis promoting factors. ${ }^{19,20} \mathrm{We}$ therefore investigated the effects of AMF/PGI on ER stressinduced cytosolic $\mathrm{Ca}^{2+}\left(\left[\mathrm{Ca}^{2+}\right]_{\text {cyt }}\right)$ and mitochondrial $\mathrm{Ca}^{2+}$ $\left(\left[\mathrm{Ca}^{2+}\right]_{\mathrm{m}}\right)$ homeostasis. $\left[\mathrm{Ca}^{2+}\right]_{\text {cyt }}$ was measured by the ratiometric $\mathrm{Ca}^{2+}$ indicator Fura-2 $\left(F_{340} / F_{380}\right)$ and $\left[\mathrm{Ca}^{2+}\right]_{\mathrm{m}}$ by Rhod-2 fluorescence $\left(F / F_{0}\right)$. After loading with $5 \mu \mathrm{M}$ Fura-2 AM or Rhod-2 AM, cells were subjected to TUN and TG perfusion. In response to either TG or TUN stimulation, AMF/PGI treatment attenuated peak amplitude without affecting total (area under the curve) TG- or TUN-induced cytosolic $\mathrm{Ca}^{2+}$ transients (Figure 6a). AMF/PGI significantly retarded cytosolic $\mathrm{Ca}^{2+}$ fluorescence decay labeled by Fura-2 

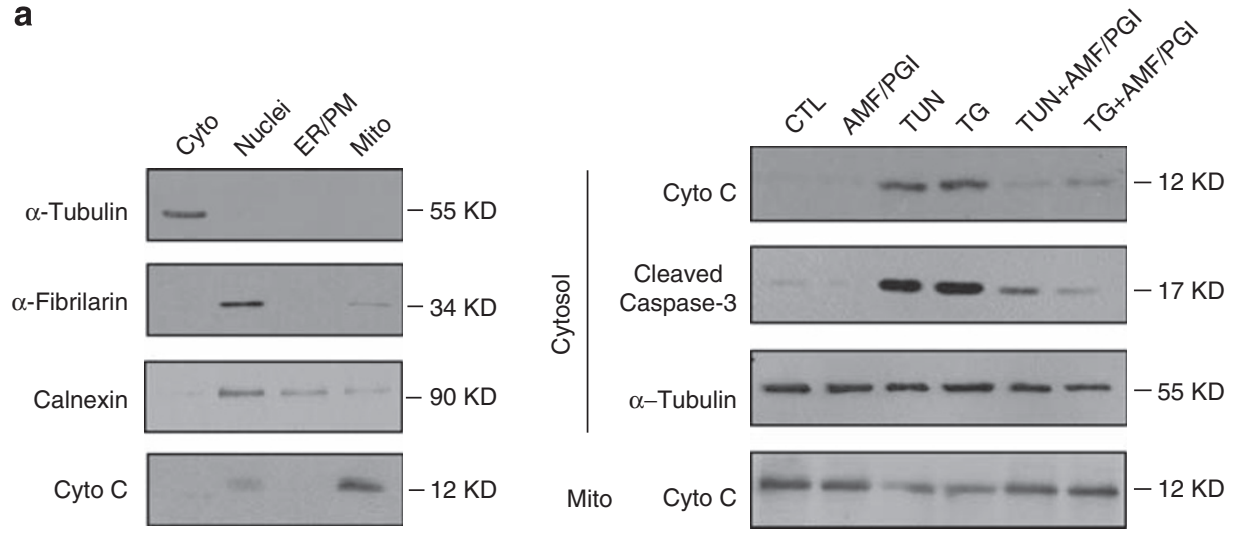

b

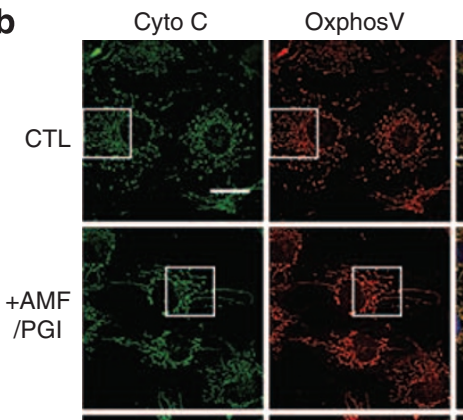

Merge

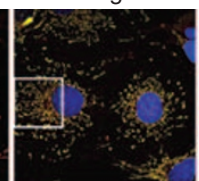

Zoom
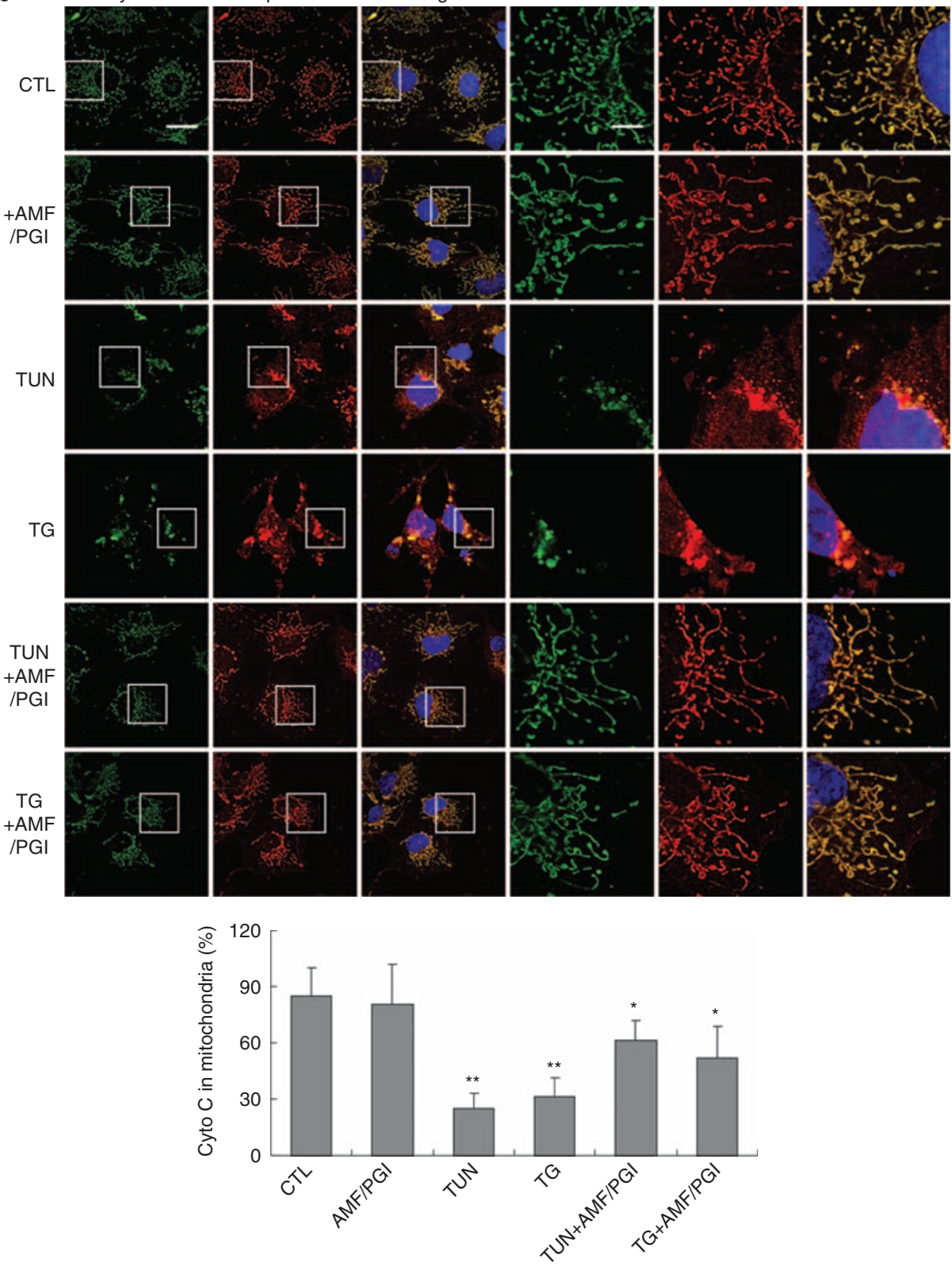
upon treatment with TG (Figure 6a). ER stress-induced mitochondrial $\mathrm{Ca}^{2+}$ dynamics were also investigated using the mitochondrial $\mathrm{Ca}^{2+}$ reporter Rhod-2. Confocal fluorescence images of Rhod-2 AM and MitoTracker Green in Cos7 cells showed essentially complete localization of Rhod-2 within mitochondria (Figure 6b). Mitochondrial $\mathrm{Ca}^{2+}$ dynamics showed that AMF/PGI treatment also reduced the rise and elevation of $\left[\mathrm{Ca}^{2+}\right]_{\mathrm{m}}$ induced by both TUN and TG stimulation (Figure 6c). These observations indicate that AMF/PGI suppresses elevation of both $\left[\mathrm{Ca}^{2+}\right]_{\text {cyt }}$ and $\left[\mathrm{Ca}^{2+}\right]_{\mathrm{m}}$ during ER stress.

Stable gp78/AMFR-specific microRNA-transfected HEK293 cells (Figure 4) were used to assess the effect of AMF/PGI on ER $\mathrm{Ca}^{2+}$ release induced by TG (Figure 7). Although AMF/PGI treatment reduced the TG induced $\left[\mathrm{Ca}^{2+}\right]_{\text {cyt }}$ transient in non-targeted control miRNA transfected HEK293 cells, it did not affect TG-induced $\mathrm{Ca}^{2+}$ release in gp78/AMFR-specific miR2 and miR3 transfected cells compared with non-targeted control HEK293 cells (NTC1 and NTC2) (Figure 7a). Interestingly, both the peak amplitude and the area under the curve (AUC) of the TG-induced $\mathrm{Ca}^{2+}$ release were significantly elevated in gp78/AMFR-specific miRNA transfected cells relative to non-targeted controls (Figure 7a).

Next, we determined whether AMF/PGI treatment also affects $\left[\mathrm{Ca}^{2+}\right]_{\text {cyt }}$ released from inositol 1,4,5-trisphosphate receptor $\left(\mathrm{IP}_{3} \mathrm{R}\right)$-mediated $\mathrm{ER} \mathrm{Ca}^{2+}$ release using $\mathrm{ATP}$ to evoke an $\mathrm{IP}_{3}$-mediated $\left[\mathrm{Ca}^{2+}\right]_{\text {cyt }}$ transient (Figure $7 \mathrm{~b}$ ). $\left[\mathrm{Ca}^{2+}\right]_{\text {cyt }}$ response to ATP stimulation was decreased significantly upon AMF/PGI treatment in control NTC1 and NTC2 cells but not in gp78/AMFR knockdown cells (miR2 and
miR3). AMF/PGI treatment attenuated the peak amplitude of ATP-evoked $\left[\mathrm{Ca}^{2+}\right]_{\text {cyt }}$ in NTC1 and NTC2 control cells but not in miR2 and miR3 gp78/AMFR knockdown cells (Figure 7b). The PI3K inhibitor LY294002 only partially reversed AMF/PGI suppression of the amplitude and did not affect the time decay of the ATP evoked $\mathrm{Ca}^{2+}$ transient (Supplementary Figure 2), consistent with previous results showing that PI3K-Akt signaling only partially affects AMF/PGI regulation of the ER stress response and cell death (Figure 5). Gp78/AMFRdependent $A M F / P G I$ stimulation therefore limits $E R \mathrm{Ca}^{2+}$ release upon $I P_{3} R$ activation that is mediated in part via $\mathrm{PI} 3 \mathrm{~K}$ signaling.

AMF/PGI decreases $\mathrm{Ca}^{2+}$ release from the ER. We then analyzed the influence of AMF/PGI on cytosolic $\mathrm{Ca}^{2+}$ dynamics in the absence of mitochondrial interactions, by treating the cells with carbonyl cyanide $m$-chlorophenylhydrazone (CCCP), a proton ionophore that uncouples the mitochondrial proton gradient and inhibits mitochondrial $\mathrm{Ca}^{2+}$ uptake. ${ }^{21}$ In control cells, addition of $1 \mu \mathrm{M}$ CCCP induced a small, but reproducible increase in cytosolic $\mathrm{Ca}^{2+}$ that corresponded to a slight downward deflection in $\left[\mathrm{Ca}^{2+}\right]_{\mathrm{m}}$ measured with Rhod-2 in untreated and AMF/PGI-pretreated cells (not shown). To investigate whether the inhibition of mitochondrial $\mathrm{Ca}^{2+}$ uptake affected AMF/PGI regulation of $\mathrm{ER} \mathrm{Ca}^{2+}$ release induced by acute SERCA inhibition and IP3R activation, we added TG and ATP 6-8 min after CCCP stimulation (Figures $8 a$ and $b$ ). In CCCP prestimulated cells, the peak amplitude of the $\mathrm{Ca}^{2+}$ transient, induced by both TG and ATP, was increased because of inhibition of mitochondrial $\mathrm{Ca}^{2+}$ uptake. However, AMF/PGI treatment a

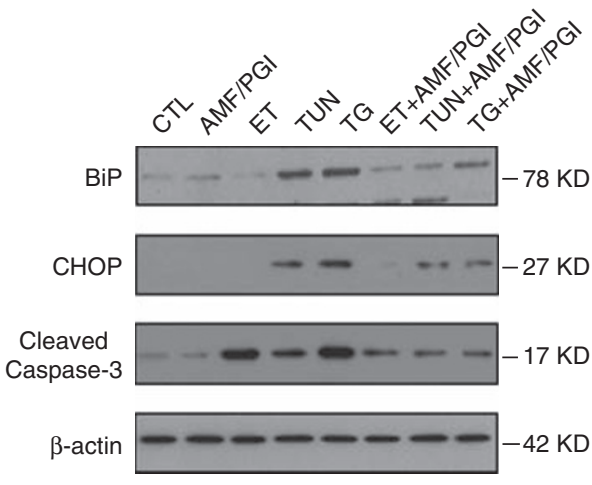

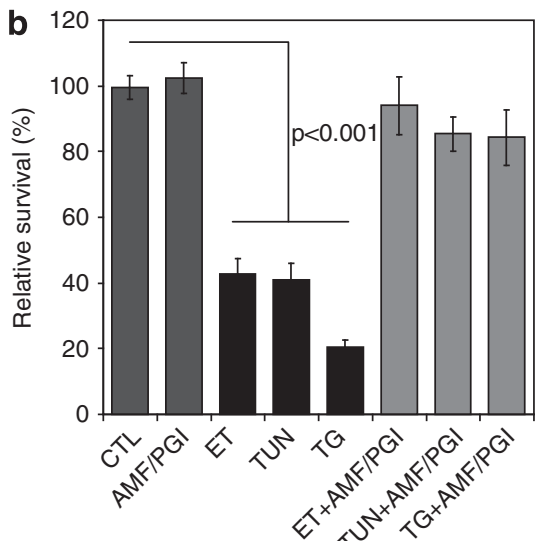

Figure 3 AMF/PGI prevents etoposide, TUN and TG-induced cell death. (a) Cos7 cells were either untreated (CTL) or pretreated with $24 \mu \mathrm{g} / \mathrm{ml} \mathrm{AMF/PGI} \mathrm{for} 8 \mathrm{~h}$ before addition of either $100 \mu \mathrm{M}$ etoposide (ET), $2 \mu \mathrm{g} / \mathrm{ml}$ TUN or $3 \mu \mathrm{M} \mathrm{TG}$. Cell lysates were immunoblotted with antibodies to BiP, CHOP, cleaved caspase-3 as well as $\beta$-actin. (b) Bar graphs show the percentage of survival after $48 \mathrm{~h}$ of cells treated as in (a) by crystal violet assay (Mean \pm S.E.M.; ${ }^{\star} P<0.05$, ${ }^{\star \star} P<0.01$ relative to CTL cells)

Figure 2 AMF/PGI prevents TUN and TG-induced apoptosis-associated events. (a) Cos7 cells were sub-fractionated into cytosol, nuclei, ER/plasma membrane, as well as mitochondrial fractions. Antibodies to $\alpha$-tubulin, $\alpha$-fibrilarin and calnexin, as well as cytochrome $c$ as markers, respectively. Cytosolic fractions of Cos7 cells, either untreated (CTL) or pretreated, with $24 \mu \mathrm{g} / \mathrm{ml} \mathrm{AMF/PGI} \mathrm{(}+$ AMF/PGl) for $8 \mathrm{~h}$ before addition of either $2 \mu \mathrm{g} / \mathrm{ml} \mathrm{TUN}$ or $3 \mu \mathrm{M} \mathrm{TG}$ for $8 \mathrm{~h}$ were immunoblotted with cytochrome $c$, cleaved caspase-3 and anti-tubulin antibodies, and mitochondrial fractions immunoblotted with cytochrome $c$ antibodies. (b) Cos7 cells treated as in a were immunofluorescently labeled with antibodies to cytochrome $c$ (red) and mitochondrial OxphosV (green) and nuclei stained with Hoechst33257 (blue). Scale bar, $40 \mu \mathrm{m}$; in box: $10 \mu \mathrm{m}$. Bar graph shows percentage of cytochrome $c$ labeling that overlaps with OxphosV-labeled mitochondria relative to total cytochrome $c$ labeling per cell (Mean $\pm S$.E.M.; ${ }^{*} P<0.05$, ${ }^{\star \star} P<0.01$ relative to $C T L$ cells) 

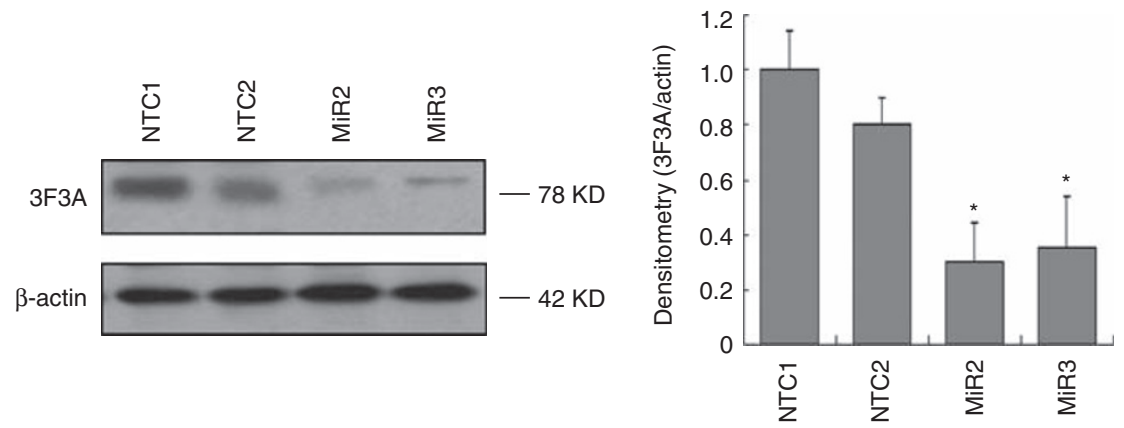

b
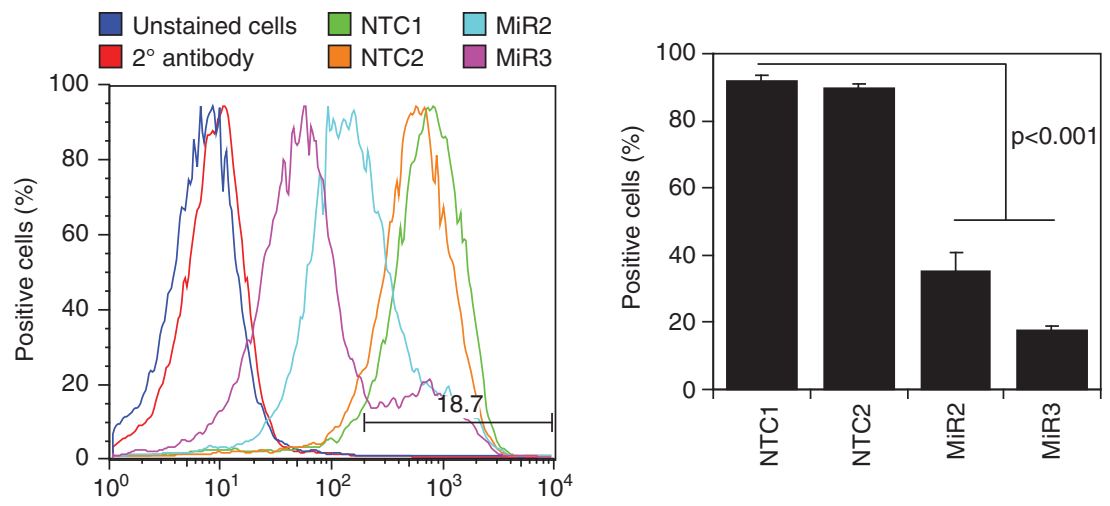

C

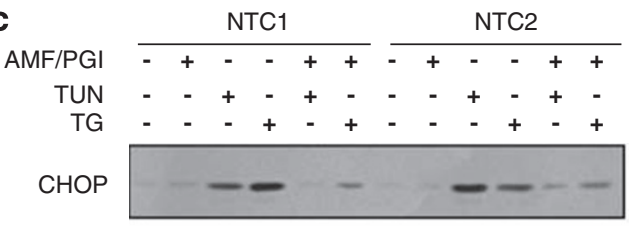

Cleaved

Caspase-3

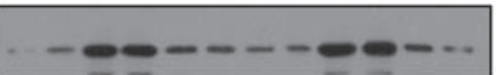

$\beta$-actin
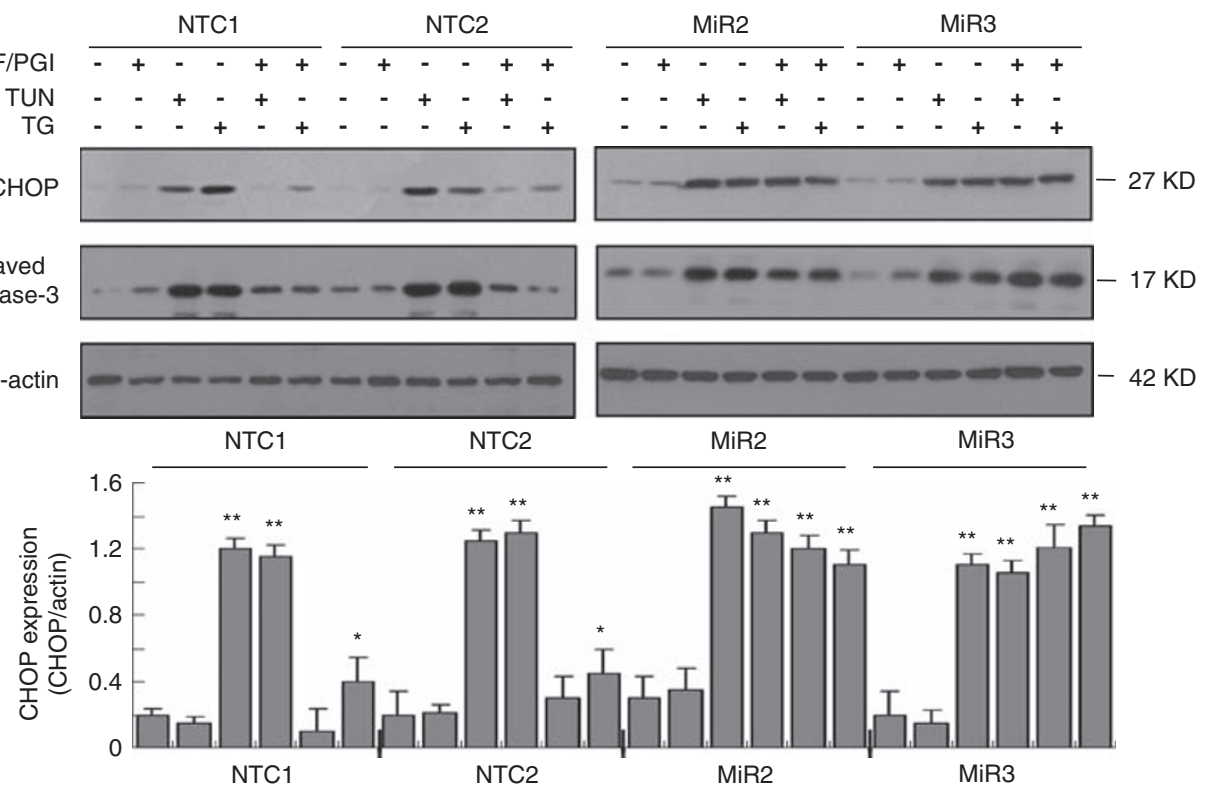

$\overline{\mathrm{M}}^{* *}$

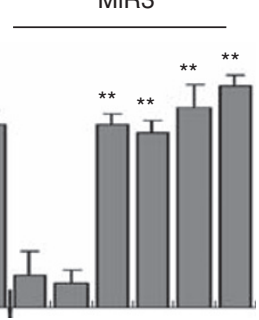

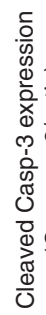

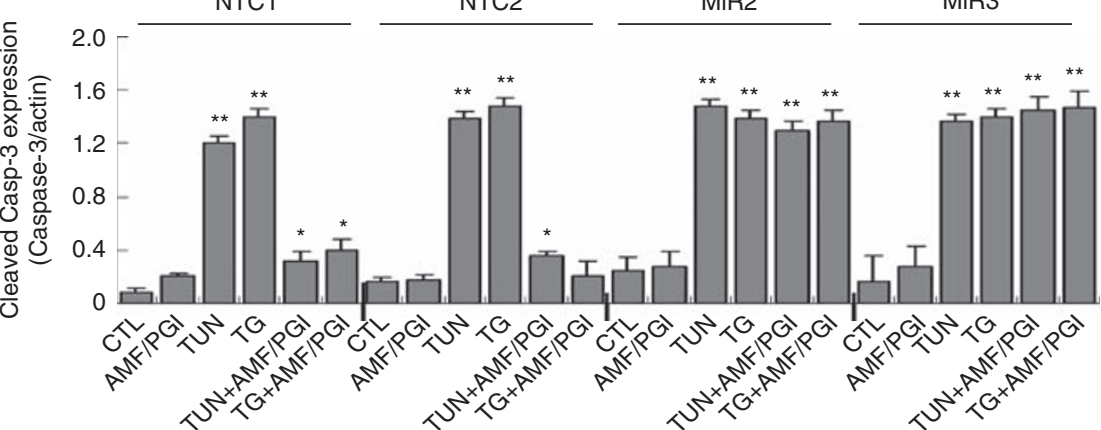


still significantly reduced $\left[\mathrm{Ca}^{2+}\right]_{\text {cyt }}$ and prolonged the time decay of the $\mathrm{Ca}^{2+}$ transient, induced by both TG and ATP, in cells prestimulated with the mitochondrial inhibitor CCCP. This indicates that AMF/PGI decrease of the cytosolic $\mathrm{Ca}^{2+}$ transient is not affected by mitochondrial $\mathrm{Ca}^{2+}$ uptake.

The effect of AMF/PGI on ER Ca ${ }^{2+}$ content $\left(\left[\mathrm{Ca}^{2+}\right]_{\mathrm{ER}}\right)$ was measured using the ER-targeted $\mathrm{Ca}^{2+}$-sensitive fluorescent protein D1ER cameleon, ${ }^{22}$ during acute SERCA inhibition by TG or ATP-evoked IP3R activation. Confocal fluorescence imaging shows essentially complete colocalization of D1ER with ER-localized KDEL monomeric red fluorescent protein ${ }^{23}$ (Figure 9a). Detection of $\mathrm{Ca}^{2+}$ transients with the D1ER cameleon required larger doses of TG and ATP $(3 \mu \mathrm{M}$ versus $10 \mu \mathrm{M}$ and $10 \mu \mathrm{M}$ versus $25 \mu \mathrm{M}$, respectively) than Fura $2 \mathrm{AM}$, suggesting that the cameleon is less sensitive than Fura 2 to TG and ATP-induced $\mathrm{ER} \mathrm{Ca}^{2+}$ release in Cos 7 cells. Both TG and ATP induced time resolved reduction of $\left[\mathrm{Ca}^{2+}\right]_{E R}$. Total TG-induced $\mathrm{ER} \mathrm{Ca}^{2+}$ release was equivalent in untreated and $A M F / P G I$ treated cells although a significant delay was seen in AMF/PGI-pretreated cells (Figure 9b). Stimulation of
Cos 7 cells with $25 \mu \mathrm{M}$ ATP results in a rapid release of $\mathrm{Ca}^{2+}$ from the $E R$ in untreated cells that was reduced both in amplitude and rate in AMF/PGI treated cells (Figure 9c). However, no significant differences in the basal cameleon FRET ratios were detected between control and AMF/PGIpretreated cells. Together, these experiments of $\mathrm{ER} \mathrm{Ca}^{2+}$ dynamics confirm that AMF/PGI treatment reduces $E R \mathrm{Ca}^{2+}$ release upon $T G$ and $I P_{3} R$ activation, consistent with the reduction in $\left[\mathrm{Ca}^{2+}\right]_{\text {cyt }}$ transients measured by Fura 2 but, importantly, indicate that AMF/PGI does not affect ER $\mathrm{Ca}^{2+}$ content.

AMF/PGI prevention of TUN and TG-induced ER stress is $\mathrm{Ca}^{2+}$ dependent. Our data suggest that gp78/AMFRmediated AMF/PGI suppression of the release of $\mathrm{ER} \mathrm{Ca}^{2+}$ stores is responsible, at least in part, for prevention of the ER stress response and associated apoptotic events. Treatment of cells with BAPTA-AM, an intracellular $\mathrm{Ca}^{2+}$ chelator, resulted in reduced $\mathrm{BiP}, \mathrm{CHOP}$ and cleaved caspase-3 expression in response to TUN and TG. It also enhanced the
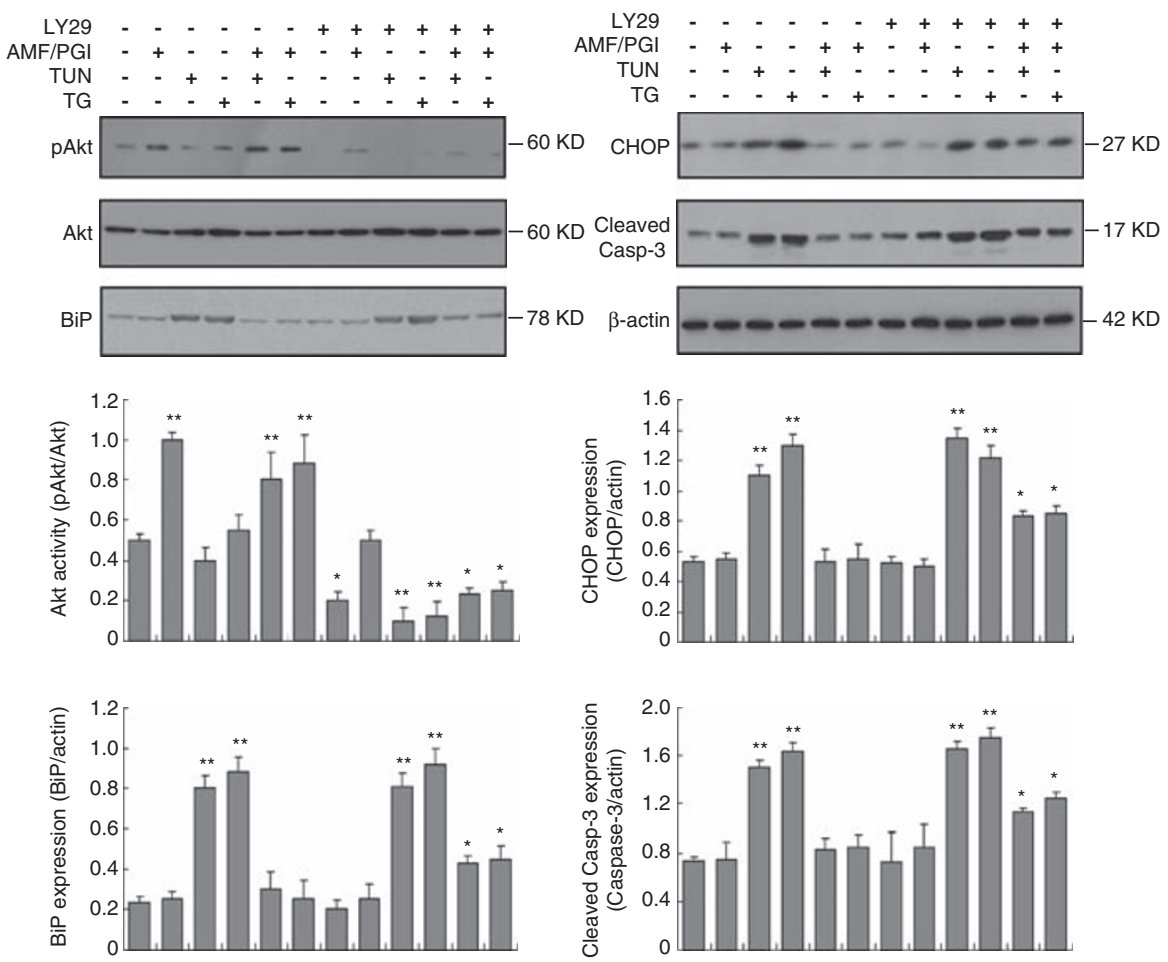

Figure 5 PI3K inhibition with LY294002 only partially reversed AMF/PGI protection against ER stress and apoptosis. Cos7 cells either untreated or pretreated with $50 \mu \mathrm{M}$ LY294002 (LY29), or pretreated with $50 \mu \mathrm{M} \mathrm{LY294002} \mathrm{(LY29)} \mathrm{plus} 24 \mu \mathrm{g} / \mathrm{ml} \mathrm{AMF/PGI} \mathrm{(+AMF/PGI)} \mathrm{for} 8 \mathrm{~h}$ before addition of either $2 \mu \mathrm{g} / \mathrm{ml}$ TUN or $3 \mu \mathrm{M} \mathrm{TG}$ for $8 \mathrm{~h}$ were immunoblotted with antibodies to pAkt, Akt, BiP, CHOP, cleaved caspase-3 antibodies, as indicated. Graphs show quantification of Akt activity (pAkt/Akt) as well as BiP, CHOP and cleaved caspase-3 expression relative to $\beta$-actin by densitometry $\left(n=3, \pm\right.$ S.E.M.; ${ }^{*} P<0.05$; ${ }^{*} P<0.01$ relative to CTL cells)

Figure 4 AMF/PGI does not protect against the ER stress response and apoptosis in gp78/AMFR knockdown cells. (a) Stable gp78/AMFR microRNA (miR2 and miR3) and non-targeted control (NTC1 and NTC2)-transfected HEK293 cells were immunoblotted with 3F3A anti-gp78/AMFR and $\beta$-actin antibodies. Reduced gp78/AMFR expression was quantified relative to $\beta$-actin by densitometry. (b) miR2, miR3, NTC1 and NTC2 cells were surface labeled with the 3F3A anti-gp78/AMFR antibody and Alexa647 anti-rat IgM secondary antibody at $4^{\circ} \mathrm{C}$ and detected by flow cytometry. Bar graph shows percentage of the 3F3A anti-gp78/AMFR-positive cells. (c) Gp78/AMFR microRNA (miR2 and miR3) or non-targeted control (NTC1 and NTC2) transfected HEK293 cells either untreated (CTL) or pretreated with $24 \mu \mathrm{g} / \mathrm{ml} \mathrm{AMF/PGI} \mathrm{(}+$ AMF/PGl) for $8 \mathrm{~h}$ before addition of $2 \mu \mathrm{g} / \mathrm{ml}$ TUN or $3 \mu \mathrm{M}$ TG for $8 \mathrm{~h}$ were immunoblotted with antibodies to CHOP and cleaved caspase-3. Graphs show quantification of CHOP (top) and cleaved caspase-3 (bottom) relative to $\beta$-actin bands by densitometry $\left(n=3, \pm\right.$ S.E.M.; ${ }^{*} P<0.05 ;{ }^{\star} P<0.01$ relative to NTC1 cells) 


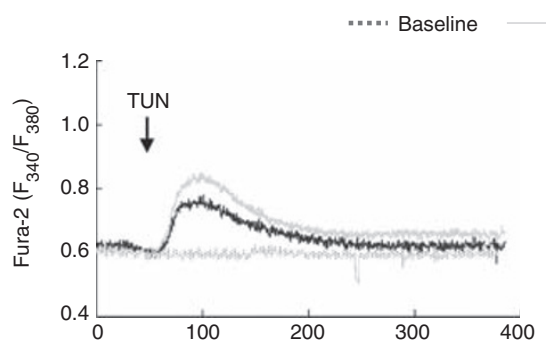

(s)
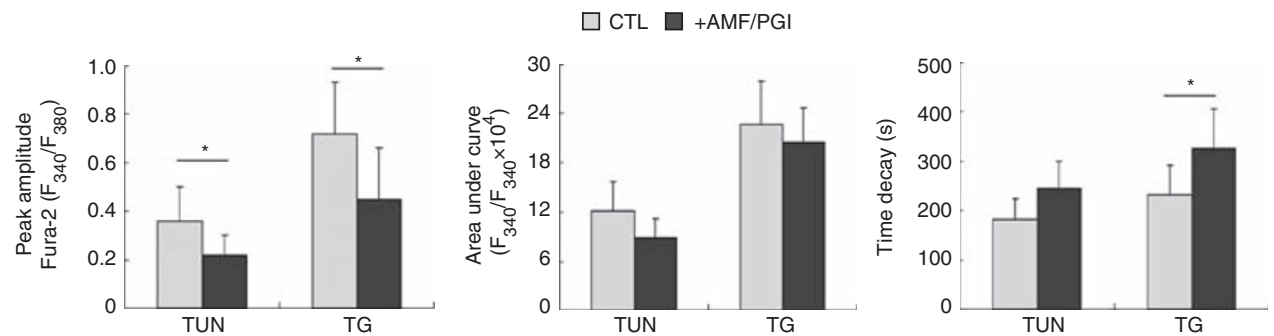

b

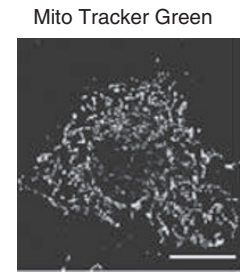

Rhod-2 AM

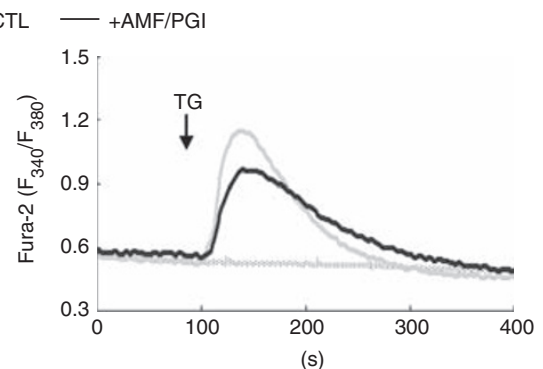

(s)
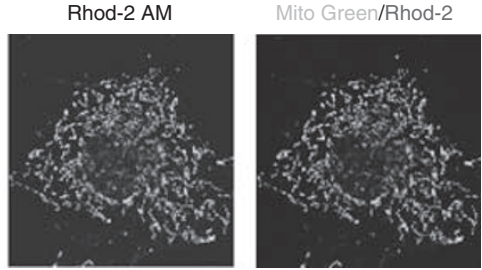

c

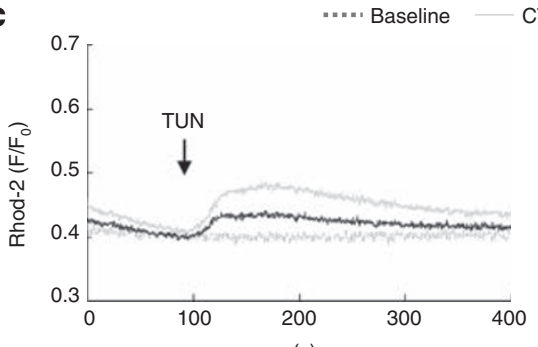

(s)
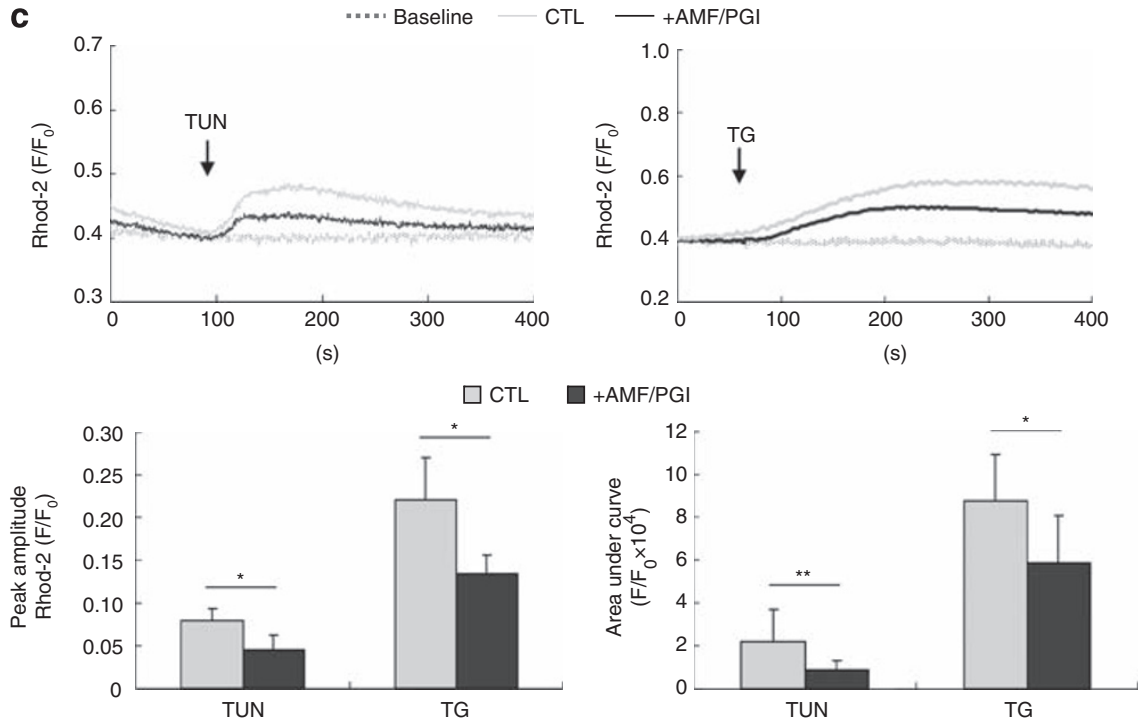

Figure 6 AMF/PGI suppresses induction of $\left[\mathrm{Ca}^{2+}\right]_{\text {cyt }}$ and $\left[\mathrm{Ca}^{2+}\right]_{m}$ by TUN and TG. (a) Representative recordings of TUN or TG-evoked cytosolic Ca ${ }^{2+}$ transients recorded by Fura-2 ratio $\left(F_{340} / F_{380}\right)$ in Cos7 cells with (dark blue) or without (light beige) AMF/PGI pretreatment $(24 \mu \mathrm{g} / \mathrm{ml} ; 8 \mathrm{~h})$, as indicated. Bar graphs show [Ca $\left.{ }^{2+}\right]_{\text {cyt }}$ peak amplitude and area under curve, as well as time decay of $\mathrm{Ca}^{2+}$ transients response to TUN or TG stimulation. (b) Confocal microscope images of Rhod-2 loaded Cos7 cells counterstained with MitoTracker Green. Scale bar, $30 \mu \mathrm{m}$. (c) Representative recordings of TUN or TG-evoked [Ca $\left.{ }^{2+}\right]_{\mathrm{m}}$ elevation recorded by Rhod-2 fluorescence $\left(F / F_{0}\right)$ in Cos7 cells with (dark blue) or without (light beige) AMF/PGI pretreatment $(24 \mu \mathrm{g} / \mathrm{ml} ; 8 \mathrm{~h})$, as indicated. Bar graphs show $\left[\mathrm{Ca}^{2+}\right]_{\mathrm{m}}$ peak amplitude and area under curve in response to TUN or TG stimulation (mean \pm S.E.M.; $60-90$ responding cells; ${ }^{\star} P<0.05,{ }^{\star \star} P<0.01$ relative to CTL cells). The color reproduction of this figure is available on the html full text version of the manuscript

effect of AMF/PGI protection on BiP, CHOP and cleaved caspase-3 expression (Figure 10a). This confirms that ER $\mathrm{Ca}^{2+}$ release is a critical element of the ER stress response and associated cell apoptosis. To determine whether reduction of $\left[\mathrm{Ca}^{2+}\right]_{\text {cyt }}$ is a key regulator of AMF/PGI protection against ER stress, cells were pretreated with
$1 \mu \mathrm{M}$ ionomycin plus $1 \mathrm{mM}$ extracellular $\mathrm{Ca}^{2+}\left(\left[\mathrm{Ca}^{2+}\right]_{\text {ext }}\right)$ that results in increased $\left[\mathrm{Ca}^{2+}\right]_{\text {cyt }}{ }^{24}$ Stable increase in $\left[\mathrm{Ca}^{2+}\right]_{\text {cyt }}$ did not result in expression of BiP, CHOP or cleaved caspase 3 nor did it generally affect expression of these ER stress markers upon TUN or TG treatment. However, BiP, CHOP and cleaved caspase 3 levels were no 

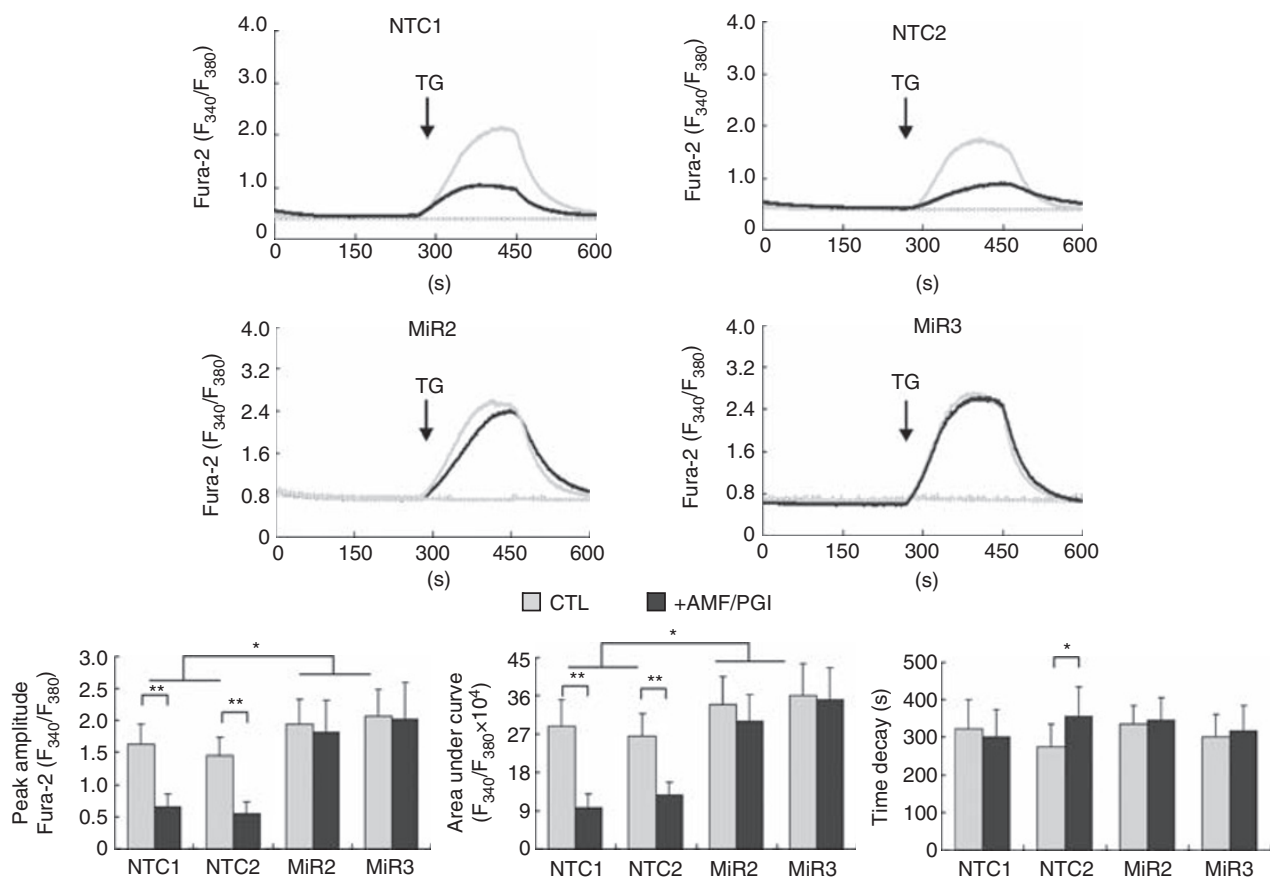

b
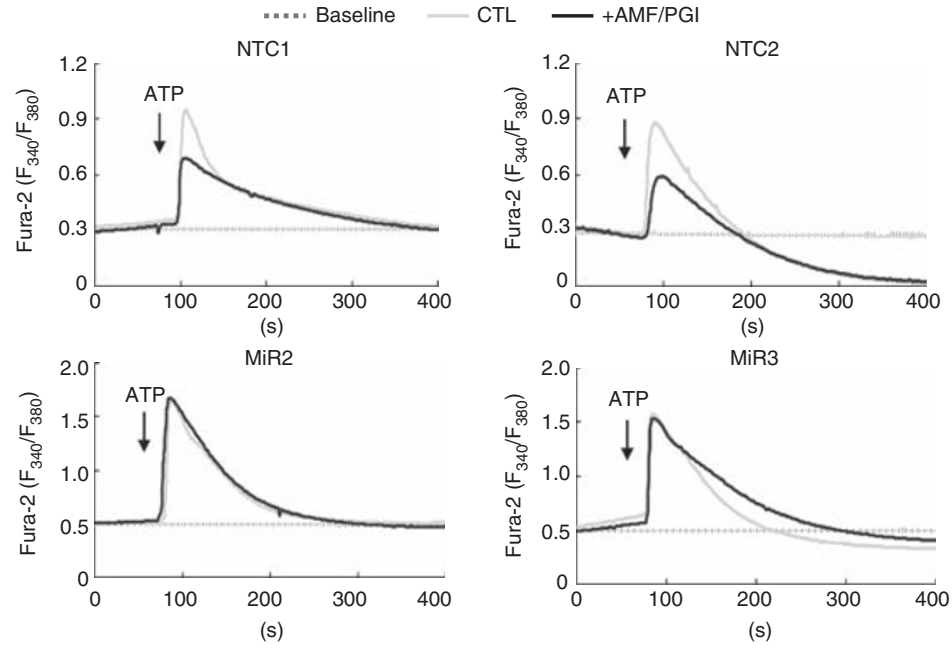

$\square$ CTL
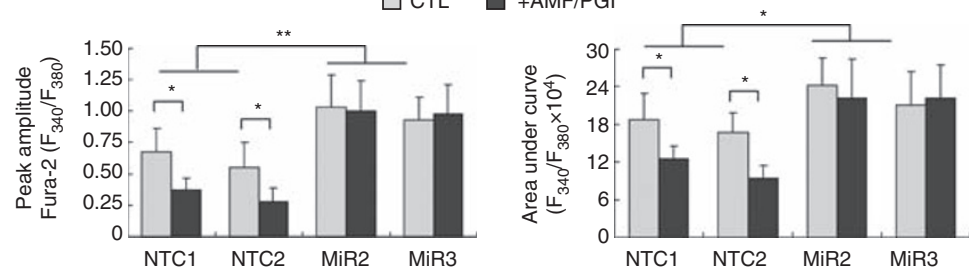

Figure 7 AMF/PGI regulation of TG and ATP-evoked $\left[\mathrm{Ca}^{2+}\right]_{\text {cyt }}$ is dependent on gp78/AMFR expression. (a) Representative recordings of TG-evoked cytosolic $\mathrm{Ca}^{2+}$ transients recorded by Fura-2 ratio $\left(F_{340} / F_{380}\right)$ in NTC1, NTC2, miR2 and miR3 cells with (dark blue) or without (light beige) AMF/PGI pretreatment $(24 \mu \mathrm{g} / \mathrm{ml} ; 8 \mathrm{~h}$ ), as indicated. Bar graphs show $\left[\mathrm{Ca}^{2+}\right]_{\text {cyt }}$ peak amplitude and area under curve as well as time decay of $\mathrm{Ca}^{2+}$ transients in response to TG stimulation in NTC1, NTC2, miR2 and miR3 cells with (dark blue) or without (light beige) AMF/PGI treatment. (b) Representative recordings of ATP-evoked cytosolic $\mathrm{Ca}^{2+}$ transients recorded by Fura-2 ratio $\left(F_{340} / F_{380}\right)$ in NTC1, NTC2, miR2 and miR3 cells with (dark blue) or without (light beige) AMF/PGI pretreatment $(24 \mu \mathrm{g} / \mathrm{ml} ; 8 \mathrm{~h})$, as indicated. Bar graphs show cytosolic Ca ${ }^{2+}$ peak amplitude and area under curve response to ATP stimulation in NTC1, NTC2, miR2 and miR3 cells with (dark blue) or without (light beige) AMF/PGI treatment. (Mean \pm S.E.M.; $100-150$ responding cells; ${ }^{*} P<0.05,{ }^{*} P<0.01$ relative to $C T L$ cells). The color reproduction of this figure is available on the html full text version of the manuscript 
a $\ldots .$. Baseline $-\mathrm{CTL}-+\mathrm{AMF} / \mathrm{PG}$

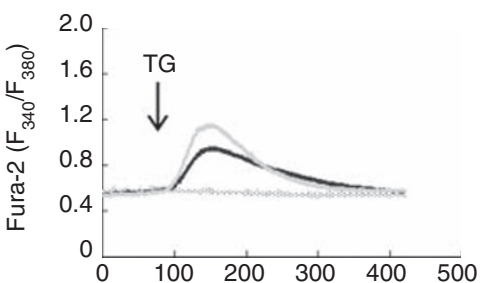

(s)

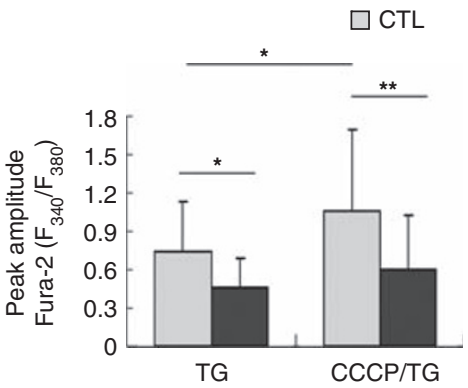

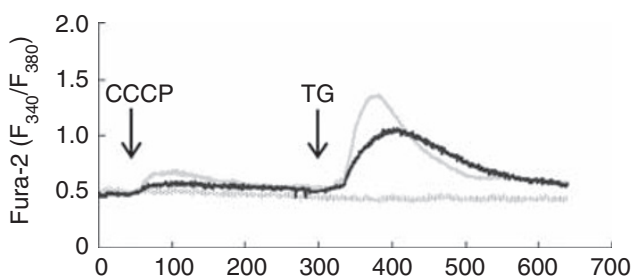

(s)

$+\mathrm{AMF} / \mathrm{PGI}$

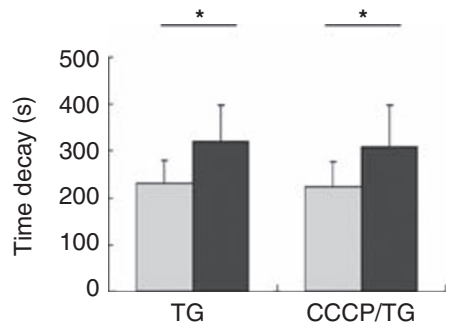

b .....Baseline $\quad$ CTL - AMF/PGI

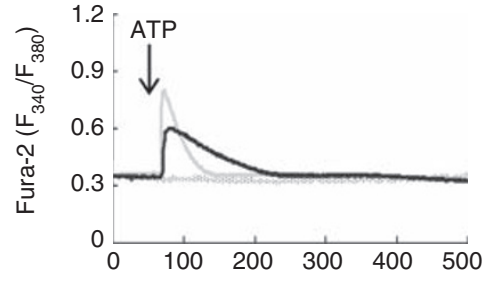

(s)

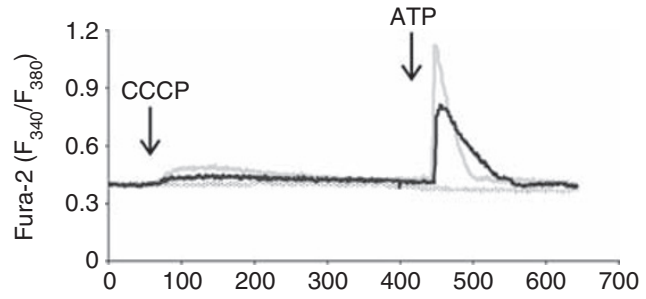

(s)
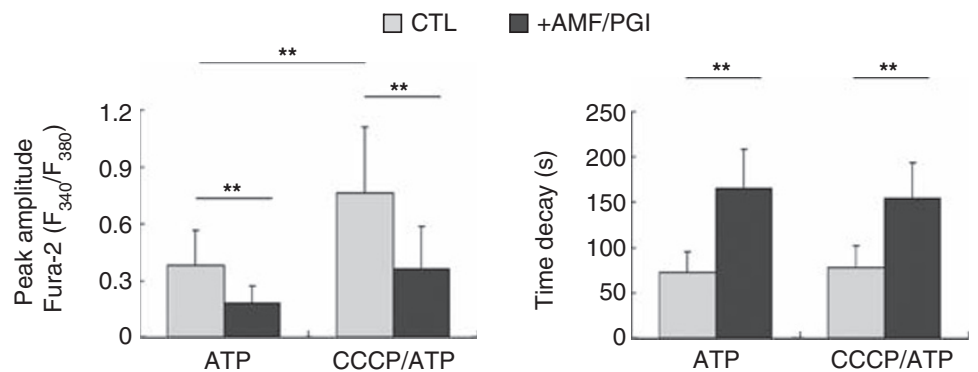

Figure 8 AMF/PGI suppression of $\left[\mathrm{Ca}^{2+}\right]_{\text {cyt }}$ is independent of mitochondrial $\mathrm{Ca}^{2+}$ uptake. (a) Representative recordings of TG alone as well as sequential CCCP and TG-induced $\left[\mathrm{Ca}^{2+}\right]_{\text {cyt }}$ dynamics were recorded by Fura-2 ratio $\left(F_{340} / F_{380}\right)$ in Cos7 cells with (dark blue) or without (light beige) AMF/PGl pretreatment $(24 \mu \mathrm{g} / \mathrm{ml} ; 8 \mathrm{~h})$, as indicated. Bar graphs show cytosolic $\mathrm{Ca}^{2+}$ peak amplitude, and time decay of $\mathrm{Ca}^{2+}$ transient in response to TG alone or CCCP and TG stimulation with (dark blue) or without (light beige) AMF/PGI pretreatment. (b) Representative recordings of ATP alone as well as sequential CCCP and ATP induced cytosolic $\mathrm{Ca}^{2+}$ dynamics recorded by Fura-2 ratio $\left(F_{340} / F_{380}\right)$ in Cos7 cells with (dark blue) or without (light beige) AMF/PGI pretreatment $(24 \mu \mathrm{g} / \mathrm{ml} ; 8 \mathrm{~h})$, as indicated. Bar graphs show [Ca $\left.{ }^{2+}\right]_{\text {cyt }}$ peak amplitude and time decay of $\mathrm{Ca}^{2+}$ transients in response to ATP alone or CCCP, and ATP stimulation with (dark blue) or without (light beige) AMF/PGI pretreatment (Mean \pm S.E.M.; ${ }^{*} P<0.05$, ${ }^{\star \star} P<0.01$ relative to $C T L$ cells). The color reproduction of this figure is available on the html full text version of the manuscript

longer attenuated by AMF/PGI pretreatment (Figure 10b). AMF/PGI, therefore prevents ER stress and promotes cell survival through regulation of ER calcium release.

\section{Discussion}

Previous reports have described a role for AMF/PGI in protection against apoptosis and cell death. ${ }^{15,25}$ The AMF/PGI receptor, gp78/AMFR, is an ER membraneanchored ubiquitin ligase (E3) that is a key component of the ERAD machinery involved in ubiquitination of ER proteins, ${ }^{26,27}$ thereby suggesting a possible role in protecting cells against ER stress. In this study, we demonstrate that AMF/PGI protects against ER stress and associated apoptosis by the intermediary of its receptor, gp78/AMFR.

Gp78/AMFR has been localized to both the plasma membrane and smooth ER by electron microscopy and to the plasma membrane by immunofluorescent labeling of viable cells using the gp78/AMFR-specific 3F3A antibody that competes with AMF/PGI for cell surface binding. ${ }^{18,28}$ Here, we show that upon gp78/AMFR knockdown, HEK293 cells present reduced cell surface 3F3A labeling and extracellular 
a

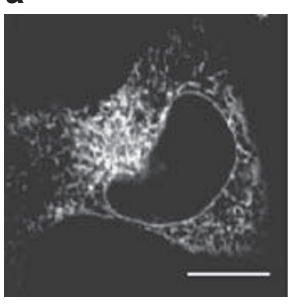

D1ER cameleon
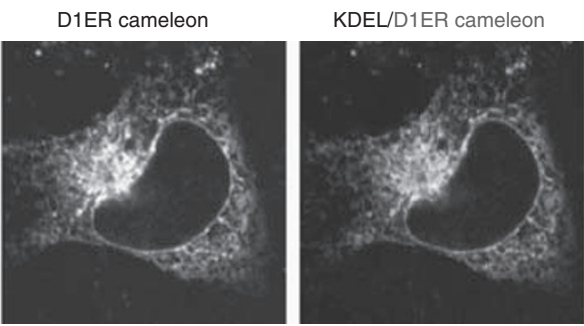

b
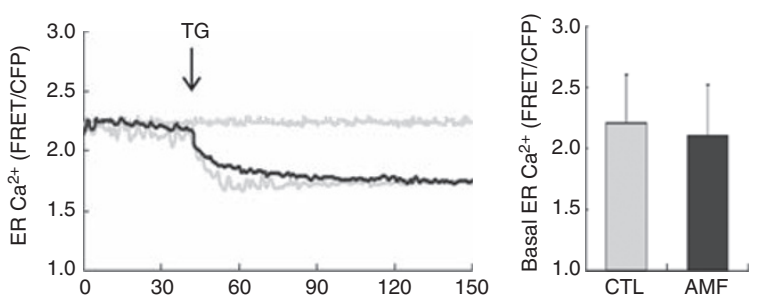

CTL
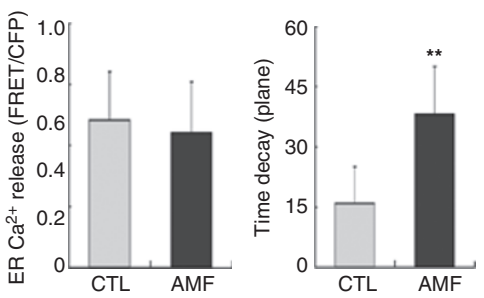

C

.... Baseline - CTL - +AMF/PGI
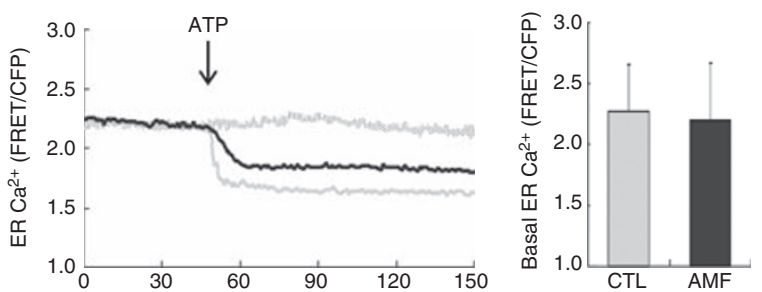

$\square \mathrm{CTL}$
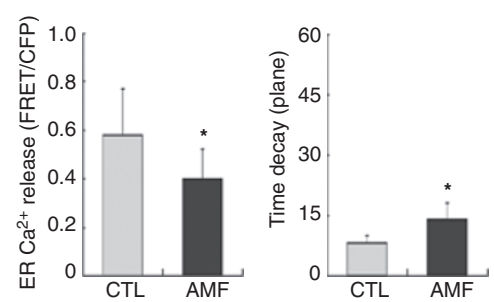

Figure 9 AMF/PGI decreases $\mathrm{Ca}^{2+}$ release from the ER. (a) Confocal images of Cos7 cells transiently transfected with an ER-targeted Ca ${ }^{2+}$-sensitive fluorescent protein D1ER cameleon and KDEL monomeric red fluorescent protein (KDEL-mRFP). Scale bar, $30 \mu \mathrm{m}$. (b and $\mathbf{c})$ Representative recordings of TG and ATP induced ER $\mathrm{Ca}^{2+}$ dynamics were recorded by the FRET-to-CFP emission ratio (FRET/CFP) in Cos7 cells with (dark blue) or without (light beige) AMF/PGI pretreatment (24 $\mu \mathrm{g} / \mathrm{ml} ; 8 \mathrm{~h}$ ), as indicated. Bar graphs show the basal ER $\mathrm{Ca}^{2+}, \mathrm{ER} \mathrm{Ca}^{2+}$ release, and time decay induced by both TG and ATP stimulation in Cos7 cells with (dark blue) or without (light beige) AMF/PGI treatment (Mean \pm S.E.M.; ${ }^{*} P<0.05$, ${ }^{\star \star} P<0.01$ relative to CTL cells). The color reproduction of this figure is available on the html full text version of the manuscript

AMF/PGI no longer prevents ER stress-induced expression of $\mathrm{BiP}, \mathrm{CHOP}$ and cleaved caspase-3. In addition, although AMF/PGI treatment dramatically attenuated the peak amplitude of ATP-evoked $\left[\mathrm{Ca}^{2+}\right]_{\text {cyt }}$ in non-targeted control cells, it had no significant effect on the peak amplitude of ATP-evoked $\left[\mathrm{Ca}^{2+}\right]_{\text {cyt }}$ in gp78/AMFR microRNA stably transfected knockdown cells. We have previously reported that expression of the gp78/AMFR ubiquitin ligase substrate KAl1 is increased and responsible for reduced proliferation of these gp78/AMFR knockdown cells. ${ }^{29}$ Loss of gp78/AMFR in these cells therefore affects both its ubiquitin ligase activity and its receptor function mediating AMF/PGI prosurvival activity.

Protein kinase $B(P K B) / A k t$ is a central factor in regulating many signaling pathways controlling cell metabolism, growth and survival. ${ }^{30}$ AMF/PGI activation of pAkt has previously been shown to mediate AMF/PGI anti-apoptosis function. ${ }^{15,18,25}$ Indeed, the ability of AMF/PGI to protect against etoposide-induced cell death that is not associated with induction of ER stress, confirms that the anti-apoptotic activity of $A M F / P G I$ is not limited to the ER stress response. Etoposide-induced apoptosis is prevented by inhibition of the PI3K-Akt pathway ${ }^{31}$ consistent with previous reports that $\mathrm{AMF} / \mathrm{PGI}$ protects against serum starvation-induced cell death in $\mathrm{NIH}-3 \mathrm{~T} 3$ fibroblasts by $\mathrm{PI} 3 \mathrm{~K} / \mathrm{Akt}$ signaling. ${ }^{15}$ However, although we found that AMF/PGI treatment induced activation of pAkt, PI3K inhibition with LY290042 only partially prevents $A M F / P G I$ protection against induction of $E R$ stress markers or AMF/PGI attenuation of $E R \mathrm{Ca}^{2+}$ release. This suggests that pAkt activation may be only one of the mechanisms by which AMF/PGI protects against ER stress.

The release of $\mathrm{Ca}^{2+}$ from $\mathrm{ER}$ and local interactions between the ER and mitochondria facilitating the transfer of $\mathrm{Ca}^{2+}$ from the ER to mitochondria represent important mechanisms of apoptosis regulation. ${ }^{11}$ The gp78/AMFRpositive smooth ER domain is closely associated with mitochondria and this interaction is regulated by $\left[\mathrm{Ca}^{2+}\right]_{\text {cyt. }}{ }^{24,32}$ In response to TG and TUN, AMF/PGI reduced the peak amplitude although not total (AUC) elevation of $\left[\mathrm{Ca}^{2+}\right]_{\text {cyt }}$ and importantly affected the rate of $\mathrm{Ca}^{2+}$ uptake to mitochondria. AMF/PGI affect on $\left[\mathrm{Ca}^{2+}\right]_{\text {cyt }}$ elevation was not however affected by mitochondrial uncoupling, suggesting that it is not related to mitochondrial association of the gp78/AMFRlabeled smooth ER domain. ${ }^{24,32}$ It was also not associated with changes in $\mathrm{ER} \mathrm{Ca}^{2+}$ content. AMF/PGI interaction with gp78/AMFR, therefore, regulates $\mathrm{ER} \mathrm{Ca}^{2+}$ release upon ER stress. To test whether $\left[\mathrm{Ca}^{2+}\right]_{\text {cyt }}$ regulates the ER stress response, we first treated cells with the cell permeable $\mathrm{Ca}^{2+}$ chelator, BAPTA-AM, and showed that it significantly reduced the expression of the ER stress markers BiP, CHOP and cleaved caspase-3 in response to either TG or TUN. Elevation 
a

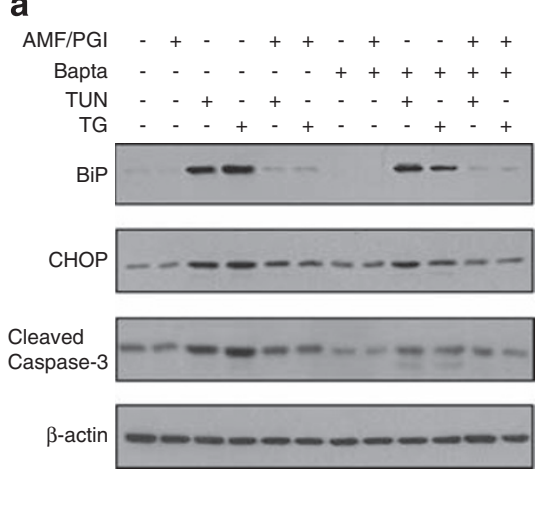

Control $\square$ Bapta
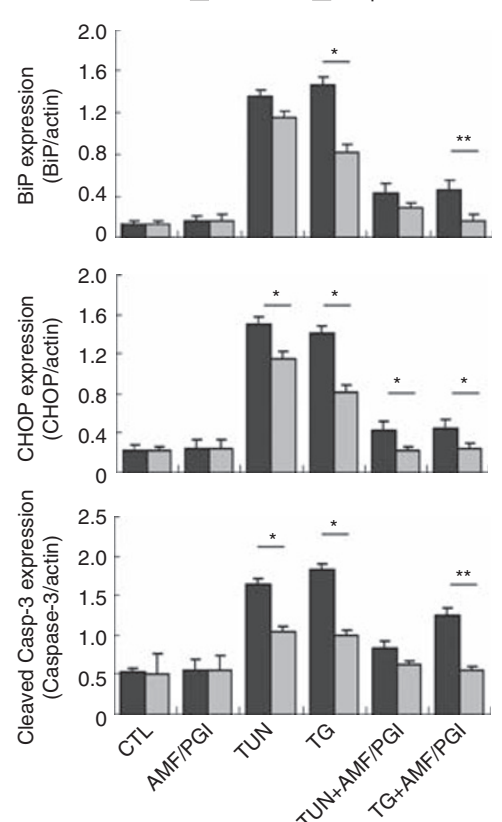

b
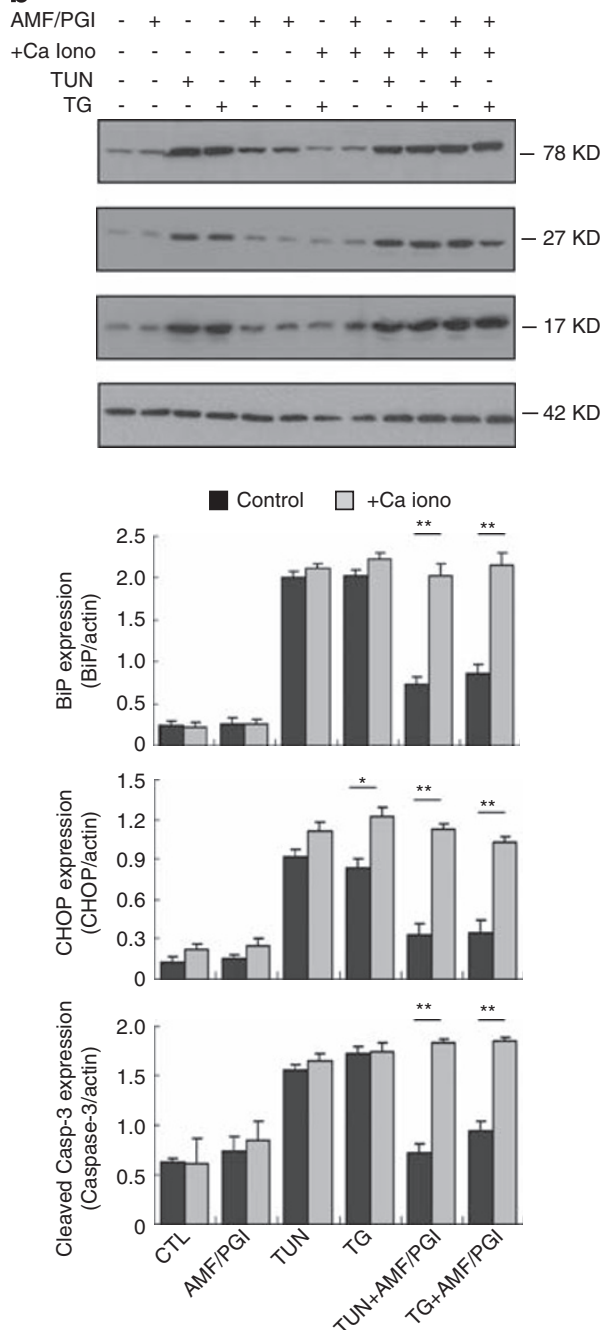

Figure $10 \mathrm{AMF} / \mathrm{PGl}$ prevention of TUN and TG-induced ER stress is $\mathrm{Ca}^{2+}$ dependent. Cos7 cells were either untreated (control) or pretreated with $24 \mu \mathrm{g} / \mathrm{ml}$ AMF/PGI for $8 \mathrm{~h}$ before addition of either $2 \mu \mathrm{g} / \mathrm{ml}$ TUN or $3 \mu \mathrm{M} \mathrm{TG}$ for $8 \mathrm{~h}$ in the presence $40 \mu \mathrm{M}$ BAPTA-AM (Bapta; a) or $1 \mathrm{mM} \mathrm{Ca}{ }^{2+}$ plus $1 \mu \mathrm{M}$ ionomycin ( + Ca lono; $\mathbf{b}$ ), as indicated. Treated cells were immunoblotted with antibodies to $\mathrm{BiP}, \mathrm{CHOP}$, cleaved caspase-3 as well as $\beta$-actin and bands quantified relative to $\beta$-actin by densitometry (Mean \pm S.E.M.; ${ }^{*} P<0.05,{ }^{*} P<0.01$ relative to control cells)

of $\left[\mathrm{Ca}^{2+}\right]_{\text {cyt }}$ by incubating cells with extracellular $\mathrm{Ca}^{2+}$ in the presence of the $\mathrm{Ca}^{2+}$ ionophore ionomycin, did not induce an ER stress response. However, stable elevated $\left[\mathrm{Ca}^{2+}\right]_{\text {cyt }}$ did prevent AMF/PGI protection against ER stress. This demonstrates that reduction of the rate of $\mathrm{ER} \mathrm{Ca}^{2+}$ release is a critical element of AMF/PGI protection against the ER stress response.

TGF- $\beta$ treatment has recently been shown to reduce the rate, but not the amplitude, of the $\left[\mathrm{Ca}^{2+}\right]_{\text {cyt }}$ response and completely depress mitochondrial $\mathrm{Ca}^{2+}$ uptake because of downregulation of $\mathrm{IP}_{3} \mathrm{R} \cdot{ }^{33}$ Regulation of ER $\mathrm{Ca}^{2+}$ release by AMF/PGI defines a novel role for an extracellular cytokine in regulation of cellular $\mathrm{Ca}^{2+}$ homeostasis. Overexpression and secretion of AMF/PGI by tumor cells induce autocrine stimulation of tumor cell motility, cell transformation and tumorigenicity; ${ }^{15}$ elevated circulating AMF/PGI levels are found in the serum of cancer patients. ${ }^{34,35}$ AMF/PGI protects against chemotherapeutic agents in vitro as well as in implanted tumors wherein it protects against paclitaxelmediated cell death. ${ }^{25,36}$ AMF/PGI interaction with gp78/ AMFR may therefore contribute to tumor cell survival and resistance to chemotherapy by limiting the ER stress response of tumor cells growing in the harsh conditions of the tumor microenvironment.

\section{Materials and Methods}

Antibodies and chemicals. The rat IgM 3F3A mAb against gp78/AMFR was as described. ${ }^{37}$ Antibodies to OxphosV were from Molecular Probes (Carlsbad, CA, USA), antibodies to CHOP, cleaved caspase 3, pAkt and Akt from Cell Signaling (Danvers, MA, USA) and to calnexin, tubulin, fibrilarin, BiP and cytochrome $c$ from Sigma (St. Louis, MO, USA). Cross-absorbed Alexa488, Alexa568 and Alexa647 or HRP-conjugated anti-mouse and anti-rabbit lgG secondary antibodies, Alexa647conjugated anti-rat IgM were from Molecular Probes. HRP-conjugated rat IgM was from Jackson ImmunoResearch (West Grove, PA, USA). BAPTA-AM and LY294002 were from Calbiochem (Gibbstown, NJ, USA). Rhod-2 AM and pluronic F-127 (PAC) and MitoTracker Green were from Invitrogen (Carlsbad, CA, USA). AMF/PGI (P9544), CCCP, etoposide, ionomycin, TUN, TG, ATP, Fura-2 AM and other reagents were from Sigma. 
Cell culture, constructs and treatments. Cos7 and HEK293 cells were grown in DMEM supplemented with $10 \% \mathrm{FBS}, 100 \mathrm{IU} / \mathrm{ml}$ penicillin, $100 \mu \mathrm{g} / \mathrm{ml}$ streptomycin, $2 \mathrm{mM} \mathrm{l-glutamine}$ and $25 \mathrm{mM}$ HEPES buffer at $37^{\circ} \mathrm{C}$ in a humid atmosphere ( $5 \% \mathrm{CO}_{2}$ and $95 \%$ air), and transfected using Effectene transfection reagent (Qiagen, Hilden, Germany). For AMF/PGI pretreatment, cells were starved overnight and incubated with fresh media containing AMF/PGI for $8 \mathrm{~h}$. Cells were subsequently treated with $2 \mu \mathrm{g} / \mathrm{ml}$ TUN and $3 \mu \mathrm{M}$ TG for 8 or $24 \mathrm{~h}$, or $100 \mu \mathrm{M}$ etoposide for $24 \mathrm{~h}$ in media containing AMF/PGI. To generate stable gp78/AMFR knockdown cell lines, pre-miRNA sequences for gp78/AMFR and non-targeting control miRNAs were cloned into pcDNA6.2-GW/ + EmGFP-miR (Invitrogen). The microRNA nucleotide sequences targeting human gp78/AMFR (GenBank accession number: NM_001144.4) correspond to the following amino acid positions relative to the initiating methionine: miR2, 271-278; miR3, 293-300. HEK293 cells were transfected with control or gp78/AMFR miRNA vectors and selected with $5 \mu \mathrm{g} / \mathrm{ml}$ blasticidin. Clones were sorted by flow cytometry and gp78/AMFR downregulation confirmed by immunoblotting and flow cytometry. The KDEL-ss-mRFP plasmid in pCDNA3.1 vector was provided by Erik Snapp (Albert Einstein College of Medicine, Bronx, NY, USA).

Immunofluorescence. Cells were fixed with 3\% paraformaldehyde, permeabilized with $0.2 \%$ Triton $\mathrm{X}-100$ and labeled with antibodies to OxphosV and cytochrome $c$ followed by species-specific fluorescent-conjugated secondary antibodies and the nuclear stain Hoechst 33257 . Cells labeled with antibodies to calnexin were fixed by precooled methanol-acetone $\left(80-20 \%\right.$, v/v, $\left.-80^{\circ} \mathrm{C}\right) .{ }^{24}$ Images were obtained using excitation with 488,543 and $633 \mathrm{~nm}$ laser lines and a $\times 100$ (NA 1.4) plan apochromat objective of an Olympus FV1000 confocal microscope (Olympus Canada, Markham, ON, Canada) and acquired using the Hi-Lo function. Cytochrome $c$ distribution to mitochondria by mask overlay (\% intensity of cytochrome $c$ labeling that overlapped with OxphosV labeled mitochondria) was quantified using ImagePro image analysis software (Media Cybernetics, Bethesda, MD, USA).

\section{Annexin V/PI double staining and gp78/AMFR surface labeling.} Labeling of cells for Annexin V/propidium iodide (PI) was performed according to the manufacturer's instructions (Roche, Basel, Switzerland). Cells were visualized by confocal microscopy ( $\times 10$ objective) using dual wavelength excitation at 488 and $568 \mathrm{~nm}$, and detection at $515-565 \mathrm{~nm}$ and $600-670 \mathrm{~nm}$ or by flow cytometry using $488 \mathrm{~nm}$ excitation and a $515 \mathrm{~nm}$ bandpass filter for fluorescence detection, and a $600 \mathrm{~nm}$ filter for PI detection. Cell surface gp78/AMFR was labeled with the 3F3A anti-gp78/AMFR antibody at $4{ }^{\circ} \mathrm{C}$ followed by Alexa-647 anti-rat IgM secondary antibody and $\mathrm{PI}$ to exclude dead cells by flow cytometry analysis, as previously described. ${ }^{18}$

Cell fractionation and western blots. Cell fractionation was performed using the mitochondrial isolation kit (Qiagen). Equal amounts of cell lysates were separated on $12 \%$ SDS-PAGE gels, transferred to nitrocellulose membranes and immunoblotted with antibodies to $\mathrm{CHOP}$, calnexin, cytochrome $c$, cleaved caspase $3, \alpha$-tubulin, $\alpha$-fibrilarin or $\beta$-actin, followed by appropriate HRP-conjugated secondary antibodies. Chemiluminescence was revealed using ECL (GE Healthcare Bio-Sciences, Piscataway, NJ, USA) and densitometry performed using Quantity One V4.62 software (Bio-Rad Laboratories, Hercules, CA, USA).

Cell viability and cytotoxicity assay. The growth inhibitory effects of TUN, TG and etoposide were determined in Cos7 cells, and quantified by measuring cell viability using a crystal violet colorimetric assay ${ }^{36}$ Cells were seeded at $5 \times 10^{3}$ cells/well in 96-well microtiter plates and allowed to attach overnight. All drugs were dissolved in DMSO, and cells were treated either with the drugs alone, or in the presence of AMF/PGI $(24 \mu \mathrm{g} / \mathrm{ml})$. Control cells received growth media or AMF/PGI $(24 \mu \mathrm{g} / \mathrm{ml})$ only. Cell growth inhibition was quantified $48 \mathrm{~h}$ post treatment. Eight-plicate cultures were analyzed in three separate experiments and the results are presented as a percentage of treated relative to untreated control cells.

Cytosolic $\mathrm{Ca}^{2+}$ measurements. Cells were plated in the wells of an Ibidi $\mu$ Slide VI flow chamber (ibidi GmbH, Martinsried (Munich), Germany, Cat No. 80606). Cells were incubated with fresh medium containing Fura-2 AM $(5 \mu \mathrm{M})$ supplied with $0.02 \%$ Pac to help disperse AM ester for 45 min at $37^{\circ} \mathrm{C}$ under an atmosphere of $5 \% \mathrm{CO}_{2}$. The flow chamber was placed on an epifluorescence/phase contrast Olympus IX71 microscope with a $\times 40$ UApo objective in a heated environmental chamber. Imaging experiments were performed at $37^{\circ} \mathrm{C}$ Extracellular solutions contained $125 \mathrm{mM} \mathrm{NaCl}, 20 \mathrm{mM}$ HEPES, $5 \mathrm{mM} \mathrm{KCl}$,
$1.5 \mathrm{mM} \mathrm{MgCl}_{2}$ and $10 \mathrm{mM}$ glucose, $\mathrm{pH} 7.4^{24}$ and were perfused rapidly using a mini pump. Cells were illuminated at alternating excitation wavelengths of 340 and $380 \mathrm{~nm}$ with a PTI high-speed random access monochromator (Photon Technology International, Birmingham, $\mathrm{NJ}$, USA). Only cells expressing a similar degree of initial Fura-2 loading were analyzed. The emitted fluorescence was recorded at $510 \mathrm{~nm}$ with a Photometric Cascade 512B CCD camera, and the calculated free $\left[\mathrm{Ca}^{2+}\right]_{\mathrm{cyt}}$ determined using a cell-free calibration curve. Images were analyzed using InVivo Analyzer V3.0 software (Media Cybernetics).

Mitochondrial $\mathrm{Ca}^{2+}$ measurements. Cells were plated in the wells of an Ibidi $\mu$ Slide VI flow chamber (ibidi $\mathrm{GmbH}$, Cat No. 80606). Cells were incubated with fresh medium containing Rhod-2 AM $(5 \mu \mathrm{M})$ supplied with $0.02 \%$ Pac in a twostep cold/warm loading protocol $\left(30 \mathrm{~min} \text { at } 4^{\circ} \mathrm{C} \text { and } 30 \mathrm{~min} \text { at } 37^{\circ} \mathrm{C}\right)^{38}$ for selective mitochondrial loading. Washed cells were analyzed in an epifluorescence/phase contrast Olympus IX71 microscope with a $\times 40$ UApo objective in a heated environmental chamber at $37^{\circ} \mathrm{C}$. Cells were illuminated at excitation wavelengths of $545 \mathrm{~nm}$ using a PTI high-speed random access monochromator (Photon Technology International). The emitted fluorescence was recorded at $575 \mathrm{~nm}$ with a Photometric Cascade 512B CCD camera (Photometrics, Tucson, AZ, USA). Images were analyzed using InVivo Analyzer V3.0 software (Media Cybernetics). Only cells expressing a similar degree of initial Rhod-2 loading were analyzed. Rhod-2 localization was visualized by counterstaining Rhod-2-loaded cells with a MitoTracker Green, and dye colocalization was confirmed by confocal microscopy.

ER Ca ${ }^{2+}$ measurement. Cells were plated on $22 \times 22 \mathrm{~mm}$ coverslips in a $35 \mathrm{~mm}$ dish and transiently transfected with the fluorescence resonance energy transfer (FRET)-based D1ER cameleon. ${ }^{22,39}$ Imaging experiments were performed at $37^{\circ} \mathrm{C}$ using a chamber system heater controller (Harvard Apparatus, Holliston, MA, USA), as described. ${ }^{39}$ Extracellular solutions contained $125 \mathrm{mM} \mathrm{NaCl}, 20 \mathrm{mM}$ HEPES, $5 \mathrm{mM} \mathrm{KCl}, 1.5 \mathrm{mM} \mathrm{MgCl}_{2}, 10 \mathrm{mM}$ glucose and $2 \mathrm{mM} \mathrm{CaCl}_{2}, \mathrm{pH} 7.4$. The cyan fluorescent protein (CFP) component of the probe was excited using a S430/25x filter (Chroma, Bellows Falls, VT, USA). CFP and FRET (i.e. YFP) emission were alternately collected using $\mathrm{S} 470 / 30 \mathrm{~m}$ and $\mathrm{S} 535 / 30 \mathrm{~m}$ filters mounted in a Sutter Lambda 10-2 filter wheel (Sutter Instrument Co., Novato, CA, USA). Changes in $\left[\mathrm{Ca}^{2+}\right]_{E R}$ were expressed as the FRET-to-CFP emission ratio, which is

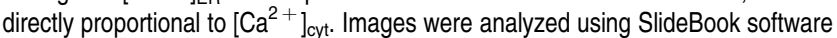
(Intelligent Imaging Innovations, Denver, CO, USA).

Statistical analyses. Data are presented as mean \pm S.E.M. One-way ANOVA was used for group-paired observations. Differences were considered statistically significant when $P<0.05$.

\section{Conflict of Interest}

The authors declare no conflict of interest.

Acknowledgements. We thank Dr Dan Luciani (UBC) for advice concerning the $\mathrm{ER} \mathrm{Ca}^{2+}$ measurements. This study was supported by a grant from the Canadian Institutes for Health Research (CIHR MT-15132). LL is the recipient of a UBC Four Year Doctoral Fellowship; TA was supported by the Karl Heinz Frenzen Stiftung and JDJ was supported by a CIHR New Investigator Award.

1. Ellgaard L, Helenius A. Quality control in the endoplasmic reticulum. Nat Rev Mol Cell Biol 2003; 4: 181-191.

2. Papp S, Dziak E, Michalak M, Opas M. Is all of the endoplasmic reticulum created equal? The effects of the heterogeneous distribution of endoplasmic reticulum $\mathrm{Ca2+-handling}$ proteins. J Cell Biol 2003; 160: 475-479.

3. Boyce M, Yuan J. Cellular response to endoplasmic reticulum stress: a matter of life or death. Cell Death Differ 2006; 13: 363-373.

4. Bernales SN, Papa FR, Walter P. Intracellular signaling by the unfolded protein response. Annu Rev Cell Dev Biol 2006; 22: 487-508.

5. Xu C, Bailly-Maitre B, Reed JC. Endoplasmic reticulum stress: cell life and death decisions. $J$ Clin Invest 2005; 115: 2656-2664.

6. Moenner $M$, Pluquet $\mathrm{O}$, Bouchecareilh $\mathrm{M}$, Chevet $\mathrm{E}$. Integrated endoplasmic reticulum stress responses in cancer. Cancer Res 2007; 67: 10631-10634.

7. Healy SJM, Gorman AM, Mousavi-Shafaei P, Gupta S, Samali A. Targeting the endoplasmic reticulum-stress response as an anticancer strategy. Eur J Pharmacol 2009; 625: 234-246. 
8. Szegezdi E, Logue SE, Gorman AM, Samali A. Mediators of endoplasmic reticulum stressinduced apoptosis. EMBO Rep 2006; 7: 880-885.

9. Zinszner H, Kuroda M, Wang X, Batchvarova N, Lightfoot RT, Remotti $\mathrm{H}$ et al. $\mathrm{CHOP}$ is implicated in programmed cell death in response to impaired function of the endoplasmic reticulum. Genes Dev 1998; 12: 982-995.

10. Hajnoczky G, Csordas G, Das S, Garcia-Perez C, Saotome M, Sinha Roy S et al. Mitochondrial calcium signalling and cell death: approaches for assessing the role of mitochondrial $\mathrm{Ca}^{+}$uptake in apoptosis. Cell Calcium 2006; 40: 553-560.

11. Pinton P, Giorgi C, Siviero R, Zecchini E, Rizzuto R. Calcium and apoptosis: ER-mitochondria $\mathrm{Ca}^{+}$transfer in the control of apoptosis. Oncogene 2008; 27 : 6407-6418.

12. Deniaud A, Sharaf el dein O, Maillier E, Poncet D, Kroemer G, Lemaire C et al. Endoplasmic reticulum stress induces calcium-dependent permeability transition, mitochondrial outer membrane permeabilization and apoptosis. Oncogene 2008; 27: 285-299.

13. Chami M, Oulès $B$, Szabadkai G, Tacine R, Rizzuto R, Paterlini-Bréchot $P$. Role of SERCA1 truncated isoform in the proapoptotic calcium transfer from er to mitochondria during ER stress. Mol Cell 2008; 32: 641-651.

14. Fairbank M, St-Pierre $P$, Nabi IR. The complex biology of autocrine motility factor/ phosphoglucose isomerase (AMF/PGI) and its receptor, the Gp78/AMFR E3 ubiquitin ligase. Mol Biosys 2009; 5: 793-801.

15. Tsutsumi S, Hogan V, Nabi IR, Raz A. Overexpression of the autocrine motility factor/ phosphoglucose isomerase induces transformation and survival of $\mathrm{NIH}-3 \mathrm{~T} 3$ fibroblasts. Cancer Res 2003; 63: 242-249.

16. Wozniak AJ, Ross WE. DNA damage as a basis for $4^{\prime}$-demethylepipodophyllotoxin-9(4,6-O-ethylidene-beta-D-glucopyranoside) (etoposide) cytotoxicity. Cancer Res 1983; 43: 120-124.

17. Mandic A, Hansson J, Linder S, Shoshan MC. Cisplatin induces endoplasmic reticulum stress and nucleus-independent apoptotic signaling. J Biol Chem 2003; 278: 9100-9106.

18. Kojic LD, Joshi B, Lajoie P, Le PU, Leung S, Cox ME et al. Raft-dependent endocytosis of autocrine motility factor is phosphatidylinositol-3-kinase-dependent in breast carcinoma cells. J Biol Chem 2007; 282: 29305-29313.

19. Kruman II, Mattson MP. Pivotal role of mitochondrial calcium uptake in neural cell apoptosis and necrosis. J Neurochem 1999; 72: 529-540.

20. Hajnoczky G, Csordas G, Madesh M, Pacher P. Control of apoptosis by $I P(3)$ and ryanodine receptor driven calcium signals. Cell Calcium 2000; 28: 349-363.

21. Tsokos J, Sans R, Bloom S. Ca2 ${ }^{+}$uptake by hyperpermeable mouse heart cells: effects of inhibitors of mitochondrial function. Life Sci 1977; 20: 1913-1921.

22. Palmer AE, Jin C, Reed JC, Tsien RY. Bcl-2-mediated alterations in endoplasmic reticulum $\mathrm{Ca} 2+$ analyzed with an improved genetically encoded fluorescent sensor. Proc Natl Acad Sci USA 2004; 101: 17404-17409.

23. Snapp EL, Sharma A, Lippincott-Schwartz J, Hegde RS. Monitoring chaperone engagement of substrates in the endoplasmic reticulum of live cells. Proc Natl Acad Sci USA 2006; 103: 6536-6541.
24. Goetz JG, Genty H, St Pierre P, Dang T, Joshi B, Sauv R et al. Reversible interactions between smooth domains of the endoplasmic reticulum and mitochondria are regulated by physiological cytosolic calcium levels. J Cell Sci 2007; 120: 3553-3564.

25. Haga A, Funasaka T, Ninaka $Y$, Raz A, Nagase $H$. Autocrine motility factor signaling induces tumor apoptotic resistance by regulations Apaf-1 and Caspase-9 apoptosome expression. Int J Cancer 2003; 107: 707-714.

26. Song BL, Sever N, DeBose-Boyd RA. Gp78, a membrane-anchored ubiquitin ligase, associates with Insig-1 and couples sterol-regulated ubiquitination to degradation of HMG CoA reductase. Mol Cell 2005; 19: 829-840.

27. Fang S, Ferrone M, Yang C, Jensen JP, Tiwari S, Weissman AM. The tumor autocrine motility factor receptor, gp78, is a ubiquitin protein ligase implicated in degradation from the endoplasmic reticulum. Proc Natl Acad Sci USA 2001; 98: 14422-14427.

28. Goetz JG, Nabi IR. Interaction of the smooth endoplasmic reticulum and mitochondria Biochem Soc Trans 2006; 340: 370-373.

29. Joshi B, Li L, Nabi IR. A role for KAl1 in promotion of cell proliferation and mammary gland hyperplasia by the gp78 ubiquitin ligase. J Biol Chem 2010; 285: 8830-8839.

30. Manning BD, Cantley LC. AKT/PKB signaling: navigating downstream. Cell 2007; 129 : 1261-1274.

31. Lee YI, Kang-Park S, Do SI, Lee YI. The hepatitis B virus-X protein activates a phosphatidylinositol 3-kinase-dependent survival signaling cascade. J Biol Chem 2001; 276: 16969-16977.

32. Wang H-J, Guay G, Pogan L, Sauve R, Nabi IR. Calcium regulates the association between mitochondria and a smooth subdomain of the endoplasmic reticulum. J Cell Bio 2000; 150: 1489-1498.

33. Pacher P, Sharma K, Csordas G, Zhu Y, Hajnoczky G. Uncoupling of ER-mitochondrial calcium communication by transforming growth factor-beta. Am J Physiol Renal Physiol 2008; 295: F1303-F1312.

34. Bodansky $\mathrm{O}$. Serum phosphohexose isomerase in cancer II. As an index of tumor growth in metastatic carcinoma of the breast. Cancer 1954; 7: 1200-1226.

35. Baumann M, Brand K, Giedl J, Hermanck P, Ruf S, Scheele J et al. Significance of serum phosphohexose isomerase in gastrointestinal cancer at different stages. Oncology 1988; 45: $153-158$.

36. Kojic LD, Wiseman SM, Ghaidi F, Joshi B, Nedev HN, Saragovi HU et al. Raft-dependent endocytosis of autocrine motility factor/phosphoglucose isomerase: a potential drug delivery route for tumor cells. PLOS One 2008; 3: e3597.

37. Nabi IR, Watanabe $\mathrm{H}$, Raz A. Identification of B16-F1 melanoma autocrine motility-like factor receptor. Cancer Res 1990; 50: 409-414.

38. Trollinger DR, Cascio WE, Lemasters JJ. Mitochondrial calcium transients in adult rabbit cardiac myocytes: inhibition by ruthenium red and artifacts caused by lysosomal loading of $\mathrm{Ca}(2+)$-indicating fluorophores. Biophys J 2000; 79: 39-50.

39. Luciani DS, Gwiazda KS, Yang TL, Kalynyak TB, Bychkivska Y, Frey MH et al. Roles of IP3R and RyR Ca2+ channels in endoplasmic reticulum stress and beta-cell death. Diabetes 2009; 58: 422-432.

\section{Supplementary Information accompanies the paper on Cell Death and Differentiation website (http://www.nature.com/cdd)}

